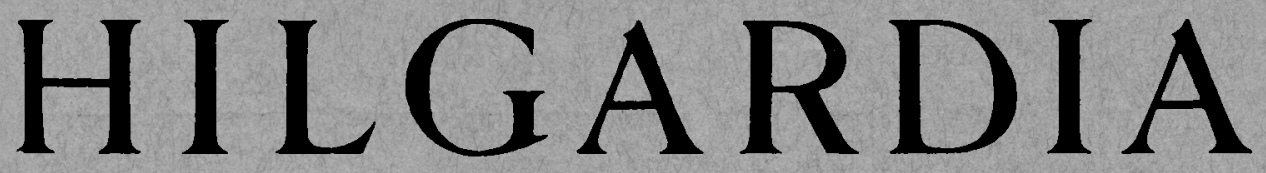

A Journal of Agricultural Science Publisbed by the California Agricultural Experiment Station

\title{
EXPERIMENTAL STUDIES ON PREDATION: DISPERSION FACTORS AND PREDATOR-PREY OSCILLATIONS
}

\author{
C. B. HUFFAKER
}

UNIVERSITY OF CALIFORNIA - BERKELEY, CALIFORNIA 
Experimental studies on the role of dispersion in predator-prey relations was studied under controlled laboratory conditions using the phytophagous mite Eotetranychus sexmaculatus as prey, and the mite Typhlo. dromus occidentalis as predator. The results are a beginning toward answering some of the theoretical questions presented to population ecologists.

The present data indicate that if an adequate environment is encompassed, the predator-prey relation is not necessarily self-annihilative, and that absolutely restrictive refuges are not essential. The results also support the view that more stable control of a population is likely to result in an environment of balanced heterogeneity than in one of simpler structure.

In this study a predator-prey relation was maintained for three successive oscillation waves before overexploitation finally ended the relation in the most complex universe or ecosystem utilized.

Some of the questions which may ultimately be answered by such studies include:

1. Are such oscillations inherently of increasing amplitude?

2. If so, are there commonly present forces which act to cancel this tendency?

3. Does the presence of other significant species in addition to the two original coactors tend to stabilize or disturb the relation?

4. What may be the effect of changes in the physical conditions upon the degree of stability or permanence of the relation?

5. Can evidence be obtained regarding the concept that the prey, as well as the predator, may benefit from the relation?

6. What is the order of influence on stability of such factors as shelter, food, disease, and natural enemies of other kinds? 


\section{H I L G A R R D I A \\ A Journal of Agricultural Science Published by \\ the California Agricultural Experiment Station \\ EXPERIMENTAL STUDIES ON PREDATION: DISPERSION FACTORS AND PREDATOR-PREY OSCILLATIONS ${ }^{1,2}$}

\section{B. HUFFAKER}

\section{INTRODUCTION}

THIS PAPER is the second covering a series of experiments designed to shed light upon the fundamental nature of predator-prey interaction, in particular, and the interrelations of this coaction with other important parameters of population changes, in general. In the first of this series (Huffaker and Kennett, 1956), ${ }^{4}$ a study was made of the predatory mites, Typhlodromus cucumeris Oudemans ${ }^{5}$ and Typhlodromus reticulatus Oudemans, and their prey species, Tarsonemus pallidus Banks, the cyclamen mite which attacks strawberries. In that paper the authors discussed in a broad way the need for detailed studies of this kind and the implications of such results for theories of population dynamics, particularly the role of predation-which role has been minimized by a number of researchers (e.g., Uvarov, 1931; Errington, 1937, 1946 ; Leopold, 1954).

A significant result of the experiments of Huffaker and Kennett (1956) was the demonstration of two types of fluctuations in density. Where predators were excluded there was a regularized pattern of fluctuations of decreasing amplitude, a result of reciprocal density-dependent interaction of the phytophagous mite and its host plant. The other, sharply contrasting type of regularized fluctuation occurred as a primary result of predation on the phytophagous mite by the predatory form. The interacting reciprocal dependence of the prey and predator populations resulted in greatly reduced densities and amplitude of fluctuations, comparing this with the status when predators were absent.

In the present effort a considerable body of quantitative data is presented. Also, the outlines of an experimental method and design sufficiently flexible for use in studying some of the principles of population dynamics are

\footnotetext{
${ }^{1}$ Received for publication August 16, 1957.

2 These results were obtained during a period of sabbatical leave in 1955 . The generous assistance of C. E. Kennett and F. E. Skinner in the preparation of the illustrations is gratefully acknowledged.

${ }^{3}$ Entomologist in Biological Control in the Experiment Station, Berkeley.

"See "References" on page 383.

${ }^{5} \mathrm{H}$. Womersley and C. E. Kennett now consider that this predator is really Typhlodromus bellinus Womersley.
} 
delineated. The specific results are discussed with respect to the much-debated question of whether the predator-prey relation is inherently self-annihilative, and the bearing on this of the type of dispersion and hazards of searching. Certain trends are exhibited; if these are further verified by later experiments they may be theoretically significant, but such possibilities will be covered only after the accumulation of additional data from this continuing series of studies.

The immediate objective in the present effort has been the establishment of an ecosystem in which a predatory and a prey species could continue living together so that the phenomena associated with their interactions could be studied in detail. Once conditions are established giving a measure of assurance against overexploitation, various other features could be introduced to study their relations to the periods and amplitudes of such oscillations in density as are demonstrated. This could include such factors as differences in temperature, humidity, or physical terrain, for example. Also, the effects could be studied of using two or more predatory species competing for the one prey species, or the simultaneous employment of two species of prey acceptable to the one predator. Many variations along these lines could be expected to furnish valuable information, and the present data represent only a beginning.

Some of the many questions that could ultimately be answered include:

1. Are such oscillations inherently of increasing amplitude?

2. Even if so, are there commonly present forces which act to cancel this tendency, and if so, what are these forces?

3 . Is the predator-prey relation adequately described by the Gause theory of overexploitation and auto-annihilation except under conditions involving immigration from other ecosystems?

4. Does the presence of other significant species in addition to the two primary or original coactors introduce a stabilizing or disturbing effect?

5 . What may be the effect of changes in the physical conditions upon the degree of stability or permanence of the predator-prey relation?

6. Can evidence be obtained supporting or refuting the concept that the prey, as well as the predators, benefits from the relation?

7. What is the order of influence on stability of population density of such parameters as shelter (from physical adversity of environment), food, disease, and natural enemies of other kinds?

There are no published accounts wherein the predator-prey relation has been followed under controlled conditions beyond a single wave or "oscillation" in density. Authorities differ as to whether this relation is inherently disoperative, leading inevitably to annihilation of either the predatory species alone or both the predator and its prey in the given universe or microcosm employed. In this controversy there is confusion as to what constitutes a suitable experimental microcosm. Published examples of such studies have been contradictory or inconclusive.

In the classic experiments of Gause (1934) and Gause et al. (1936), the predator and prey species survived together only under quite arbitrary conditions-either when a portion of the prey population was protected by a 
"privileged sanctuary" or when reintroductions were made at intervals. Gause concluded that such systems are self-annihilative, that predators characteristically overexploit their prey, and that in nature immigrants must repopulate the local environments where this has occurred. He argued against the theory that repeated waves or oscillations conforming to mathematical formulae have an inherent meaning in the absence of immigrations.

Nicholson $(1933,1954)$ advocates the contrary view, and he and Winsor (1934) criticized Gause's experiments on the grounds that the universes or microcosms he employed were too small to even approximate a qualitative, to say nothing of a quantitative, conformity to theory.

DeBach and Smith (1941) conducted a stimulating experiment with a special type of predator (an entomophagous "parasite") in which they tested the biological parameter of searching capacity against Nicholson's formula. The results conformed to theory very neatly. Ecologists consider the results as based upon too arbitrary assignments or omission of other biological parameters - such as length of a generation, fecundity, undercrowding phenomena at very low densities, et cetera. However, their work remains a strikingly successful pioneer endeavor in this field, and their method of isolating the variables other than searching was productive.

In the present study an effort was made to learn if an adequately large and complex laboratory environment could be set up in which the predator-prey relation would not be self-exterminating, and in which all the biological parameters are left to the free play of the interacting forces inherent in the experiment, once established. Consequently, the procedure was to introduce the prey species and the predator species only at the initiation of an experiment and to follow population trends afterward without any further introductions or manipulations. No assignments of biological parameters were made. Furthermore, no areas restrictive to the predators were furnished. Food "conditioning" is the only complicating variable and this disturbance was minimized by the methods used. However, as experiments were terminated because of the annihilative force of predation in the initial, limited universes employed, the conditions set up for subsequent experiments were made progressively more complex in nature and the areas larger.

\section{EXPERIMENTAL DESIGN AND PROCEDURE}

\section{General Aspects}

The six-spotted mite, Eotetranychus sexmaculatus (Riley), was selected as the prey species and the predatory mite Typhlodromus occidentalis Nesbitt as the predator. These species were selected because successful methods of rearing them in the insectary were already known, and because earlier observations had revealed this Typhlodromus as a voracious enemy of the six-spotted mite. It was known to develop in great numbers on oranges infested with the prey species, to destroy essentially the entire infestation, and then to die en masse. At this author's suggestion, Waters (1955) had studied the detailed biology of both species and had followed population trends on individual 


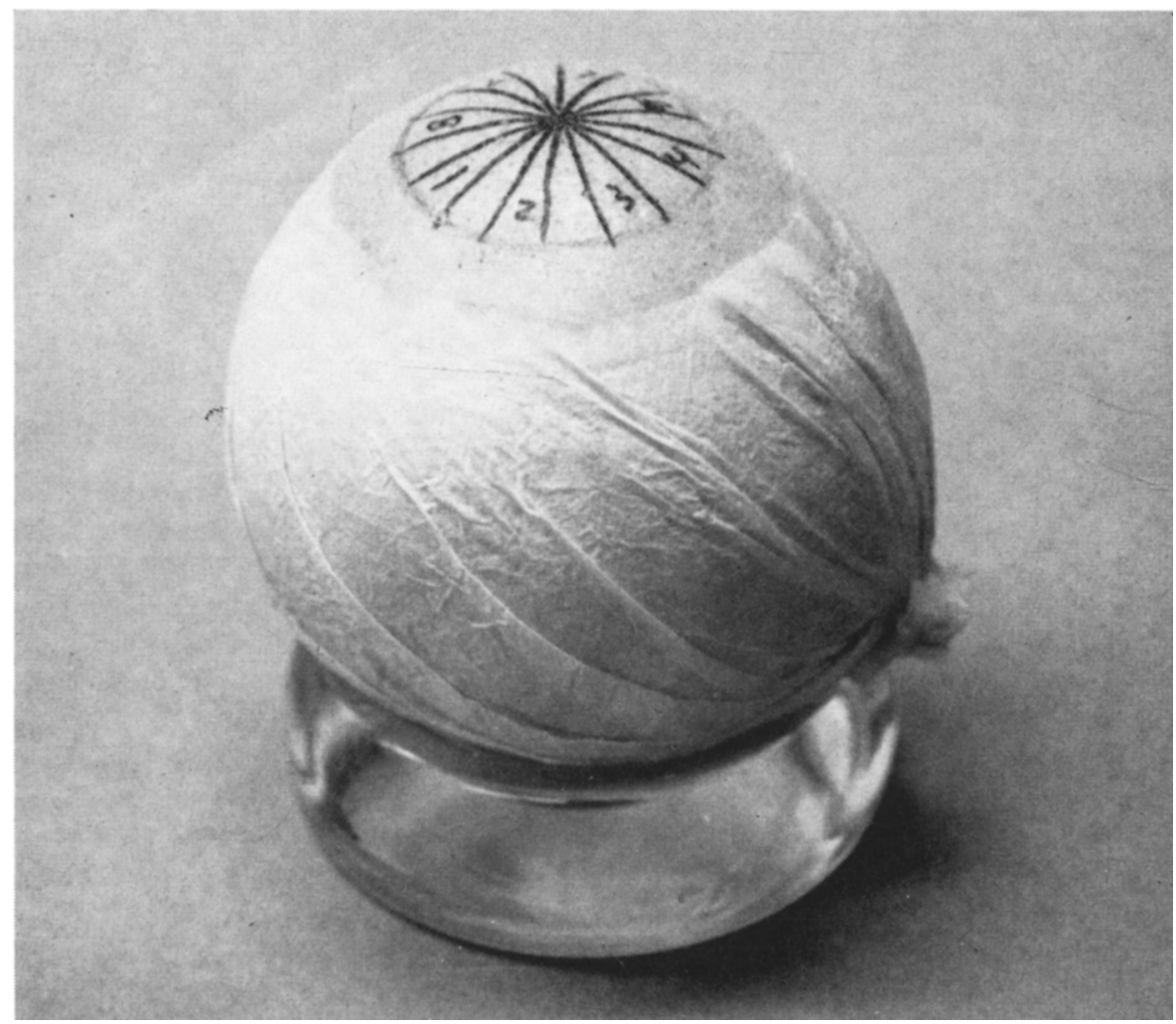

Fig. 1. Orange wrapped with paper and edges sealed, ready for use with sample areas delineated. (Photograph by F. E. Skinner.)

oranges as a problem in predator-prey dynamies. ${ }^{6}$ This work was valuable in the conduct of the present research.

Uniformity in certain characteristics was maintained throughout the course of these experiments. Temperature was maintained constant at $83^{\circ} \mathrm{F}$. Relative humidity varied some but was not allowed to fall below 55 per cent. There were no means of dehumidifying the room, but automatic humidity controls assured against the damaging action of low humidity. The room was kept dark.

Uniformity in total areas of the universes was achieved by utilizing various combinations of oranges and rubber balls equivalent to them in size (see figs. $1,2,3$, and 4, for examples). This made it possible to change either or both the total primary food substrate (orange surface) and the degree of dispersion of that substrate without altering the total area of surfaces in the universes or the general distribution of units of surface in the systems. The object was to make it possible to vary the surface of orange utilized and its

'The design of Waters' experiments, however, was not such as to answer some of the questions posed by this study. His universes were restricted and simple, with no possibility for return to oranges by individuals leaving them by "dropping off." His results were similar to those of Gause, but he drew several conclusions which are more generally applicable than some of Gause' generalizations. 


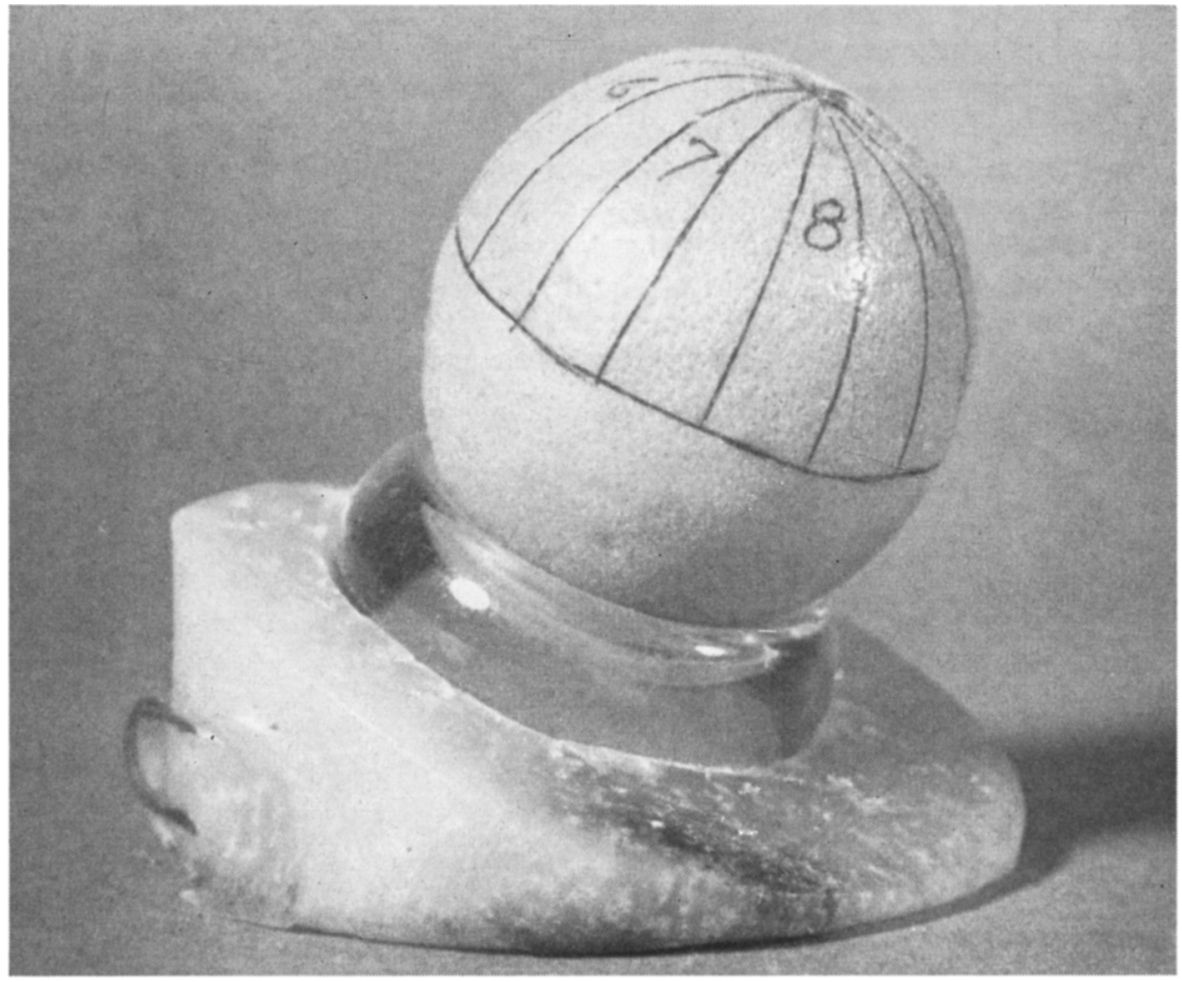

Fig. 2. Orange with lower half covered with paraffin and exposed upper half with sample areas delineated. Fuzzy surface is due to lint used. Paraffin base serves to bring all areas into focus under the microscope (see text). (Photograph by F. E. Skinner.)

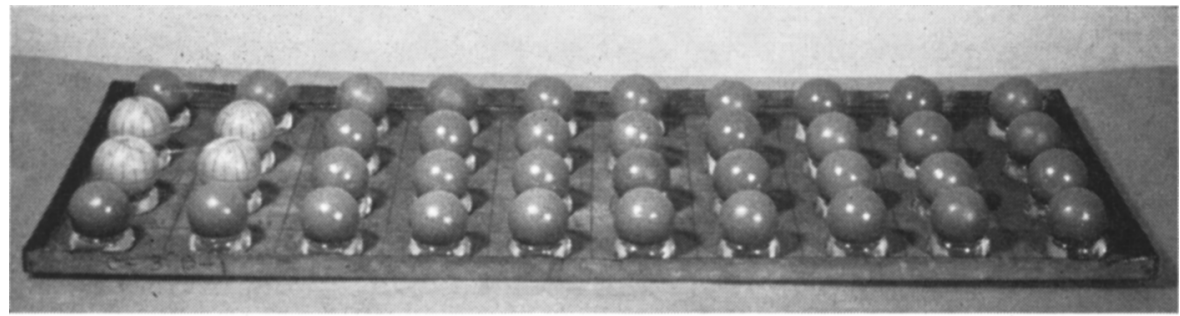

Fig. 3. Four oranges, each with half-surfaces exposed (see fig. 2), grouped and joined with a wire loop, remainder of positions occupied by waxed, linted rubber balls, a 2orange feeding area on a 4-orange dispersion, grouped. (Photograph by F. E. Skinner.) 
distribution in order to complicate the search for food by both the prey and predator. Thus, a simple environment where all the food was concentrated to a maximum degree (fig. 3 ) could be compared with one in which the food was dispersed according to arbitrary degrees (fig. 4) throughout the system (the oranges being arranged or randomly dispersed among the rubber balls). Also, the quantity of food as well as the nature of the dispersion were varied by covering the oranges with paper to whatever degree desired, the paper being wrapped tightly, twisted and tied, and with circular holes then cut to expose the required areas of orange surface. The edges of the holes and the twisted ends were then sealed with paraffin to exclude the mites from gaining entrance to the covered surfaces. An example of an orange ready for use is shown in figure 1 .

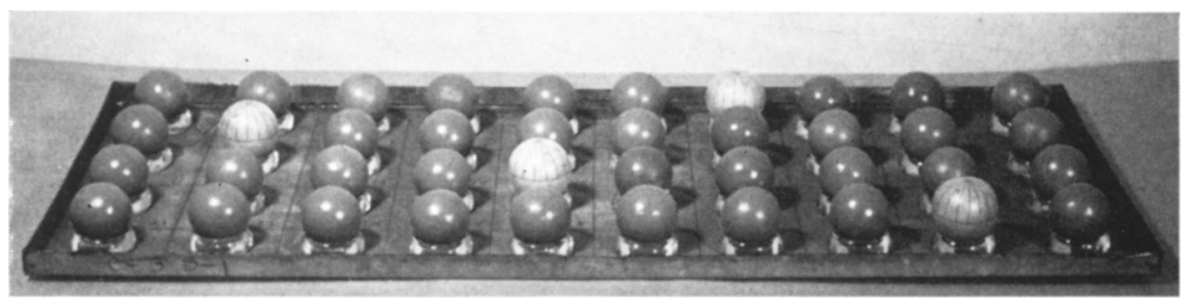

Fig. 4. Four oranges, each with half-surfaces exposed (see fig. 2), randomized among the 40 positions, remainder of positions occupied by waxed, linted rubber balls-a 2-orange feeding area on a 4-orange dispersion, widely dispersed. (Photograph by F. E. Skinner.)

Considerable difficulty was encountered in arriving at a proper means of limiting the feeding area on a given orange. The first method tried was to dip the naked oranges in hot paraffin, leaving the desired areas clean. Considerable time was lost during the operation of the first two series of experiments because the oranges which were almost completely coated with paraffin or, later, even those covered with polyethylene bags, rotted before results could be obtained. It was only subsequent to this difficulty that a good grade of typing paper was tried. The paper proved to be an excellent material but somewhat difficult to form to an adequately smooth, mite-excluding covering. This fault was corrected by very slightly dampening the paper before wrapping and by using paraffin as a sealing material.

A primary difficulty foreseen in this study was that of replenishing the food material as it is used or becomes conditioned. Under the conditions employed, oranges last from 60 to 90 days as suitable food for the prey species if not fed upon to the extent of conditioning. However, a heavy infestation can deplete an orange of suitable nourishment and thus condition it within three to five days. It is relatively impracticable to remove the food factor as a limiting feature. Also, localized food depletion by the prey species just as much as food depletion by the predator species is inherent to the natural scene. Yet, it was hoped that depletion of food could be evaluated and reduced to a minor position in limiting the populations. It was desirable to build into the design a schedule of removal of old oranges, whether or not conditioned, and their replacement by fresh ones. This would make possible a continuing system which would not automatically end if and when the orig- 
inal oranges became too old or conditioned. Also, by the use of eareful notes on conditioning and by comparing universes where predators were introduced with universes which had none, conclusions could be drawn as to the relative importance of any interference occasioned by the conditioning of the oranges. The schedule consisted of removing $1 / 4$ of the oranges (the oldest or obviously most unsuitable ones) at intervals of 11 days. This gave a complete change of oranges every 44 days-a period amply in advance of general unsuitableness because of age alone. One restriction was imposed. No significant last of a population in a subsection was removed-any such orange otherwise "due" being held another 11 days.

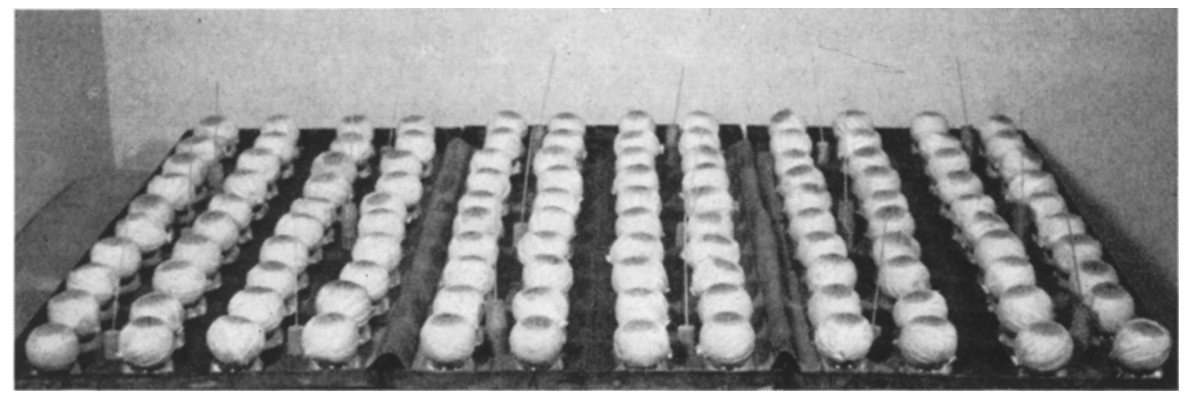

Fig. 5. 120 oranges, each with 1/20 orange-area exposed (method of fig. 1), occupying all positions in a 3-tray universe with partial-barriers of vaseline and wooden posts supplied-a 6-orange feeding area on a 120-orange dispersion with a complex maze of impediments (see text). Trays are broadly joined by use of paper bridges. (Photograph by F. E. Skinner.)

An estimate was made from general observations and the results of Waters (1955) that an orange area equivalent to that of two oranges, each $2 \frac{1}{2}$ inches in diameter, would be adequate, as a beginning, to study the predatorprey relation. With this premise, the smallest working basis for this design would utilize four oranges with each orange half-covered. This is because it was not desired to change more than $1 / 4$ of the food surfaces at a given time; that is, one of the four oranges used. This made it impossible to go to the ultimate in simplicity of searching and greatest concentration of the orange surfaces by utilizing only two whole, uncovered oranges.

Each universe in the earlier experiments conformed to this pattern, but certain other changes were made later. Each universe consisted of a flat metal tray, 40 inches long and 16 inches wide, with a side wall 1 inch in height and with 40 Syracuse watch glasses on each of which rested either an orange or a rubber ball (see figs. 3, 4, and 5). The positions were arbitrarily arranged in rows to conform to the dimensions of the trays -10 oranges and/or balls along the long dimension and four along the short dimension. This gave a center to center distance of 4 inches. The upper rim of the bordering wall of cach tray was kept coated with white petroleum jelly to prevent movement of mites into or out of the trays. The predators and prey were therefore. free to move onto or leave oranges or rubber balls but were not permitted to leave or enter the universes.

Lint-covered oranges as used by Finney (1953) to culture the six-spotted 
mite were used in all the experiments. The lint gives an ideal physical environment for propagation of the species employed. It produces an orange surface similar to the covering of fine hairs and setae on the surfaces of many plant leaves. However, it also adds to the complexity of the searching problem for the predator and increases the maximal potentials in populations of both species. In addition, it was noted that populations on well-linted oranges were less subject to the adverse effects of low humidity.

Initially, experiments were arranged in duplicate; check units having the prey species alone were carried along with those having both the prey and predator species. However, as the experiments developed, certain universes automatically terminated, and new ones not synchronized chronologically or exactly comparable in other respects were substituted. With each new universe employed, some change designed to give a better chance for perpetuation of the predator and prey in the system was incorporated. These changes were based on deductive thought and trial and error processes. During this study, the author had the good fortune to have Dr. A. J. Nicholson of Australia, one of the world's leading theoreticians on population dynamics, examine the experiments, and he confirmed the view that these changes must largely be decided upon by trial and error processes. Concerning some points it was not known whether a given change would detract or add to the chances of perpetuation of the predator-prey relations-such is the reciprocal interdependence of some actions.

The exposed area of an orange was in the form of a circle which was stamped on the orange by use of a shell vial of the proper size and an inking pad. The space between the outer edge of this line was then covered with hot paraffin and joined with the edge of the paper surrounding the hole. Several layers of hot paraffin were laid down as a seal by use of a small camel's hair brush. The oranges were then placed in a refrigerator for about 1 hour to chill the surfaces. Upon removal to the laboratory, only two or three oranges at a time, condensation on the surfaces was sufficient for dampening the point of an indelible pencil as lines were drawn on the surfaces of the exposed circular areas. Diameter lines were drawn in this way, dividing the area into 16 or more sampling sections with each section numbered. This greatly facilitated the counting of the populations. The counting had to be done under a stereoscopic microscope.

When the populations reached very low levels, total populations were counted, but normally the populations were counted on only $1 / 4$. or $1 / 8$ of the total surfaces. The sample areas were taken in each case so as to be distributed evenly around the face of the "clock," but the first section to be counted was always taken at random.

Considering the universes employing oranges with all or one half their surfaces exposed, much difficulty was initially encountered in manipulating the oranges under the microscope so that the populations in the sample areas could be viewed fully, and without disturbance of the populations. However, the device shown in figure 2 solved this problem. It consists of a paraffin block cut so that one side at its highest point is $1 \frac{1}{2}$ inches and is tapered to the other side which is only $1 / 8$ inch high. An orange placed on the Syracuse 
watch glass, which sits loosely in a depression in the block, can then be turned by rotating the watch glass so that any desired sample area can be brought into focus without touching or awkwardly manipulating the orange.

\section{Sampling Procedure}

Sampling of partial areas and populations in the present study was necessary in order to reduce the time required in counting large populations. Hence, the populations in most cases were sampled. Statistical analyses of test examples furnished estimates of the loss in confidence occasioned by such sampling.

It was found that a population estimate based upon a subsample of a given size on an orange is more reproducible if composed of two or more noncontiguous areas evenly distributed among the position (see fig. 1). This method was used in all sampling.

TABLE 1

ANALYSIS OF VARIANCE FOR DATA OF APRIL 26 IN FIGURE 8.

\begin{tabular}{c|r|r|r|r|r|r|r|r|r|r|r|r|r|r|r|r|r|r|r|r}
\hline \hline \multicolumn{1}{c|}{ Orange no. } & 1 & 2 & 3 & 4 & 5 & 6 & 7 & 8 & 9 & 10 & 11 & 12 & 13 & 14 & 15 & 16 & 17 & 18 & 19 & 20 \\
\hline Subsample & & & & & & & & & & & & & & & & & & & & \\
$1 \ldots \ldots \ldots \ldots \ldots \ldots$ & 20 & 2 & 1 & 1 & 2 & 2 & 8 & 1 & 20 & 15 & 17 & 0 & 16 & 7 & 6 & 2 & 1 & 0 & 2 & 0 \\
$2 \ldots \ldots \ldots \ldots \ldots \ldots$ & 17 & 2 & 5 & 1 & 2 & 4 & 6 & 5 & 30 & 8 & 9 & 4 & 5 & 2 & 7 & 8 & 0 & 0 & 0 & 4 \\
$3 \ldots \ldots \ldots \ldots \ldots \ldots$ & 21 & 2 & 9 & 3 & 0 & 3 & 0 & 0 & 32 & 4 & 8 & 7 & 1 & 0 & 8 & 1 & 0 & 0 & 0 & 1 \\
$4 \ldots \ldots \ldots \ldots \ldots \ldots$ & 23 & 1 & 1 & 5 & 0 & 2 & 4 & 3 & 24 & 2 & 15 & 5 & 2 & 4 & 7 & 1 & 0 & 0 & 1 & 1 \\
\hline Sums............ & 81 & 7 & 16 & 10 & 4 & 11 & 18 & 9 & 106 & 29 & 49 & 16 & 24 & 13 & 28 & 12 & 1 & 0 & 3 & 6 \\
\hline
\end{tabular}

Source V. d.f. S.S. M.S. Total $\quad 79 \quad 4,160$

Between oranges $193,679194^{*}$

Within oranges $\quad 60 \quad 481 \quad 8$
Standard error general mean, $\mathrm{S} \overline{\mathbf{x}}_{\mathrm{g}}=0.81$, or $14.6 \%$ of $\overline{\mathbf{x}}_{\mathrm{g}}$.

Standard error between oranges, $\mathrm{S} \overline{\mathrm{x}}_{\mathrm{o}}=6.9$, or $31.2 \%$ of $\overline{\mathbf{x}}_{\mathrm{o}}$.

Using this method of assignment of the positions of the subsamples on an orange, examples of data were analyzed to establish whether the withinorange variance which is associated with subsampling is significantly greater than the variance between the oranges. The data of Table 1 for April 26 illustrate the nature of the variance, and show that the within-orange variance, which is associated with the subsamples, is very small, and that if greater accuracy were required, it could best be achieved by counting populations on more oranges rather than by altering the technique of subsampling on a given orange.

It was therefore decided that the samples include every orange, but the subsamples on each orange would be varied with the approximate densities 
of the populations encountered, the usual proportion being $1 / 2$ or $1 / 4$ the total exposed area on each orange.

Early in the study in deciding upon the technique of sampling, the entire population of the prey species was counted on a representative group of 44 orange units, with each unit exposing $1 / 20$ of an orange area. This population was thus finite and known. The data used were for July 5 from the experiment illustrated in figure 18. The mean, $\mathrm{x}$, for the 44 items was 6.95 mites per exposed area, with a standard error of \pm 1.09 , which is 15.7 per cent of the mean. This standard error reflects the variance inherent to the particular type of conglomerate distribution exhibited by such populations.

In order to determine if the subsamples could be used to estimate the total populations, half-area counts were first used. Series of six half-area random lots of the component items were drawn from the aforementioned total population on the 44 representative oranges. The means, standard errors, and the coefficient of variation were then compared with the values based upon the total known population. These statistical parameters were little changed: the standard errors being $\pm 0.52, \pm 0.68, \pm 0.65, \pm 0.63, \pm 0.56$, and \pm 0.64 , respectively, as compared with a half-value of \pm 0.55 for the total population; the coefficient of variation varying from 16.2 per cent to 19.3 per cent compared with 15.7 per cent (the coefficient of variation of the whole population); and the means, as estimates of the mean of the total population, averaging only 4.7 per cent higher or lower than the corresponding halfvalue for the total population-the range being from 3.3 to 7.8 .

A test was also made to determine if a further reduction in the counting (to $1 / 4$ the total area) would give adequate estimates of the population when large universes or high populations were encountered. Both the predator and prey populations on August 1 (see fig. 18) were analyzed for this purpose.

It should be noted that some basic change had occurred between July 5 and August 1 contributing to greater skewness of distribution. This is revealed by an increase in the coefficient of variation from 15.7 per cent for the whole population count of July 5 (analysis just discussed) to 22.3 per cent for the large sample count on August 1. The six subsamples of reduced size taken on August 1 closely approximated the large sample in coefficient of variation, these being 23.3 per cent, 23.9 per cent, 23.3 per cent, 22.8 per cent, 23.3 per cent, and 23.5 per cent, respectively.

There are two probable reasons for this change in the nature of the variation. In the former instance, the predators had not yet been introduced while they were significantly active on August 1. The predator-prey relation characteristically contributes to skewness, colonial, or conglomerate distribution. Also, the prey were introduced into the universe in equal numbers on all oranges at the initiation of the experiment, and some time is necessary for the typical conglomerate distribution to become manifested, even disregarding predation. Therefore, the larger, although uniform coefficient of variation of the samples on August 1 are not the result of inadequate sampling technique but express the nature of the distribution of the population.

Comparing the prey populations of the $1 / 4$-area samples with the composite "total" or $1 / 2$-area sample on August 1, the standard errors were little 
changed: these being $\pm 2.43, \pm 2.63, \pm 2.70, \pm 2.67, \pm 2.60$, and \pm 2.48 , respectively, for the six $1 / 4$-area samplings, as compared with a half-value of \pm 2.39 for the $1 / 2$-area sample; the coefficient of variation, previously listed, varied only from 22.8 per cent to 23.9 per cent, compared with 22.3 per cent for the sample of double size; and the means, as estimates of the mean of the population present on twice the area, averaging only 4.7 per cent higher or lower than the corresponding half-value for the larger sample-the range being from 1.6 to 9.2 .

Predator populations were more variable than were the prey populations. The standard error for total counts of the large ( $1 / 2$ area) sample was \pm 0.254 , with a half-value of \pm 0.127 , while the values for the counts made on six $1 / 4$-area samples were $\pm 0.117, \pm 0.150, \pm 0.155, \pm 0.167, \pm 0.153$, and \pm 0.151 . The coefficient of variation also varied more than the corresponding values for the prey population, these being 24.6 per cent, 34.6 per cent, 32.6 per cent, 29.0 per cent, 32.8 per cent, and 27.2 per cent, compared with 26.7 per cent for the sample of double size. The same was true for the means, these values, as estimates of the mean of the population on the larger area, averaging 5.7 per cent higher or lower, but having a range from 0.0 to 12.1.

When such ranges of error relating to the various observed points in the illustrations are considered, comparing positions of high and low densities, it is obvious that there is adequate accuracy in the estimates to establish the validity of the major trends or patterns of population change exhibited with respect to the predators and their prey in the various experiments. Yet, obviously, some of the minor, inconsistent changes following no general trend in time may be the result of inadequacy of sampling, and hence have a random character independent of predation.

\section{RESULTS}

A group of eight universes was started on February 4 and February 10. These were duplicates of an earlier group - which, as previously stated, had to be discarded because the oranges were rotting-except that the covering used on the oranges was part polyethelene material and part paraffin, rather than paraffin alone. This group also had to be discarded except for certain universes which utilized four oranges each, and these were half-covered with paraffin. Oranges only half-covered with paraffin proved satisfactory, and those units were retained.

A basic idea in this study has been the comparison of results when the plant food (oranges) is readily accessible (massed in one location in the universes) with other examples having the food widely dispersed, with the problems of dispersal and searching thus made more difficult for both the predators and the prey. The control universes which reveal the approximate levels of density of the prey species in the absence of predation, thus limited by the availability of food, were followed under several conditions of dispersion of the food material. These are considered representative of densities permitted by the respective levels of availability of food; and the degree to which the prey fail to reach these densities under the pressure of predation in the other universes is a measure of the effect of that predation. 
The specific designs of experiments which differ from the general methods and procedures discussed previously will be covered, along with the results obtained, under each type of universe employed.

\section{Densities of Prey and Fluctuations in the Absence of Predation}

The following three universes were used as a measure of the population dynamics of the prey species in the absence of predators.

A. Predators Absent, Simplest Universe, Four Large Areas of Food, Grouped at Adjacent, Joined Positions. In this universe a 2-orange feeding area on a 4-orange dispersion was employed, and the unit was started February 10 and ended July 1 (see figs. 3 and 6 ). The initial colony was established by placing 20 female six-spotted mites, $E$. sexmaculatus (the prey species), on one of the four oranges. Movement to the other oranges was delayed until the period between March 4 and March 8 at which time the orange originally colonized was beginning to become conditioned and migrants had started moving. Thus, on a feeding area as large as a half orange, overpopulation may be delayed for about three weeks. This is significant with respect to attempts to establish self-sustained existence of both the predator and its prey in a universe. If the prey do not move readily or at least are not moving from some arenas rather readily most of the time, the predators only have to locate a colony arena and stay with it until it is overexploited, resulting in its own extinction and possibly that of its prey as well. On a given orange, this predator commonly overexploits such a colony in much less than the three week period required for conditioning pressure under these conditions (see figs. 9, 10, and 11). This question will be discussed further in relation to the data of Subsections F, G, H, and I of Section II, and it led to the arrangements used in those universes.

Regarding densities, the approximate mean population reached in this universe (fig. 6) was 9,400 E. sexmaculatus (all stages), or 4,700 per orangearea. Two major peaks above that level, once population growth had progressed that far, and two subsequent, resultant depressions below it occurred. These indicate a trend of a somewhat "oscillatory" nature due to occurrence of waves of maximal or excessive utilization of the food, followed by inadequate food to support the high levels. This trend may be only a carry-over result of the arbitrary unnaturally high abundance of entirely "unconditioned" or unutilized food at the initiation of the experiment, in interaction with the pattern of orange replacement. This example was not continued long enough to learn if the degree of such fluctuations would continue undiminished in amplitude or whether an inherent oscillation associated with factors of dispersal and population density under related conditions is a real feature of well-established, long-term system-i.e., ones which have reached internal balance, or relative calm.

These results do establish that a relatively high mean population is characteristic of this experimental arrangement, contrasted to that which results when predators are present. Perhaps a sizeable part of the large fluctuations may be the result of variations in the nutritional qualities of the 


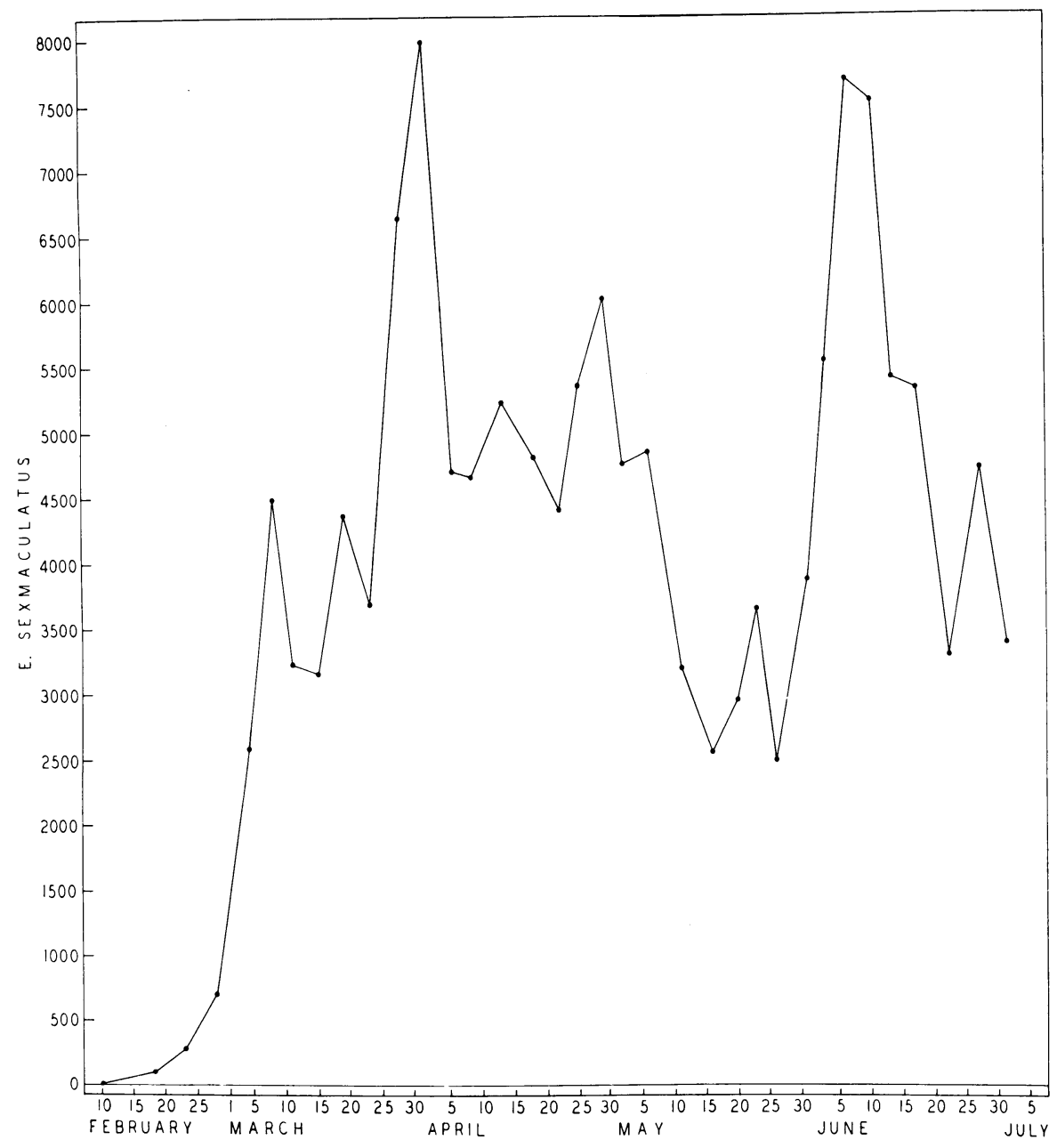

Fig. 6. Densities per orange-area of Eotetranychus sexmaculatus in the absence of predators in the simplest universe used, with four large areas of food (orange surface) grouped at adjacent, joined positions-a 2-orange feeding area on a 4-orange dispersion (see fig. 3 and text, Subsection A, Section I of "Results").

oranges supplied during the course of the experiment. It is known that oranges do vary in nutritional value for this mite. Beginning with March 30, at which time the population had first attained maximal utilization of the food, the oranges afterward removed in the replacement scheme were invariably fully utilized or conditioned. This full utilization is probably the most important reason why the mean level of this population was higher than that in the next two universes discussed. In fact, it was characteristic that the populations on these oranges reached conditioning levels well in advance of the dates for removal of the respective oranges, and such conditioning pressure, sometimes from two oranges at once, accomplished very prompt natural 


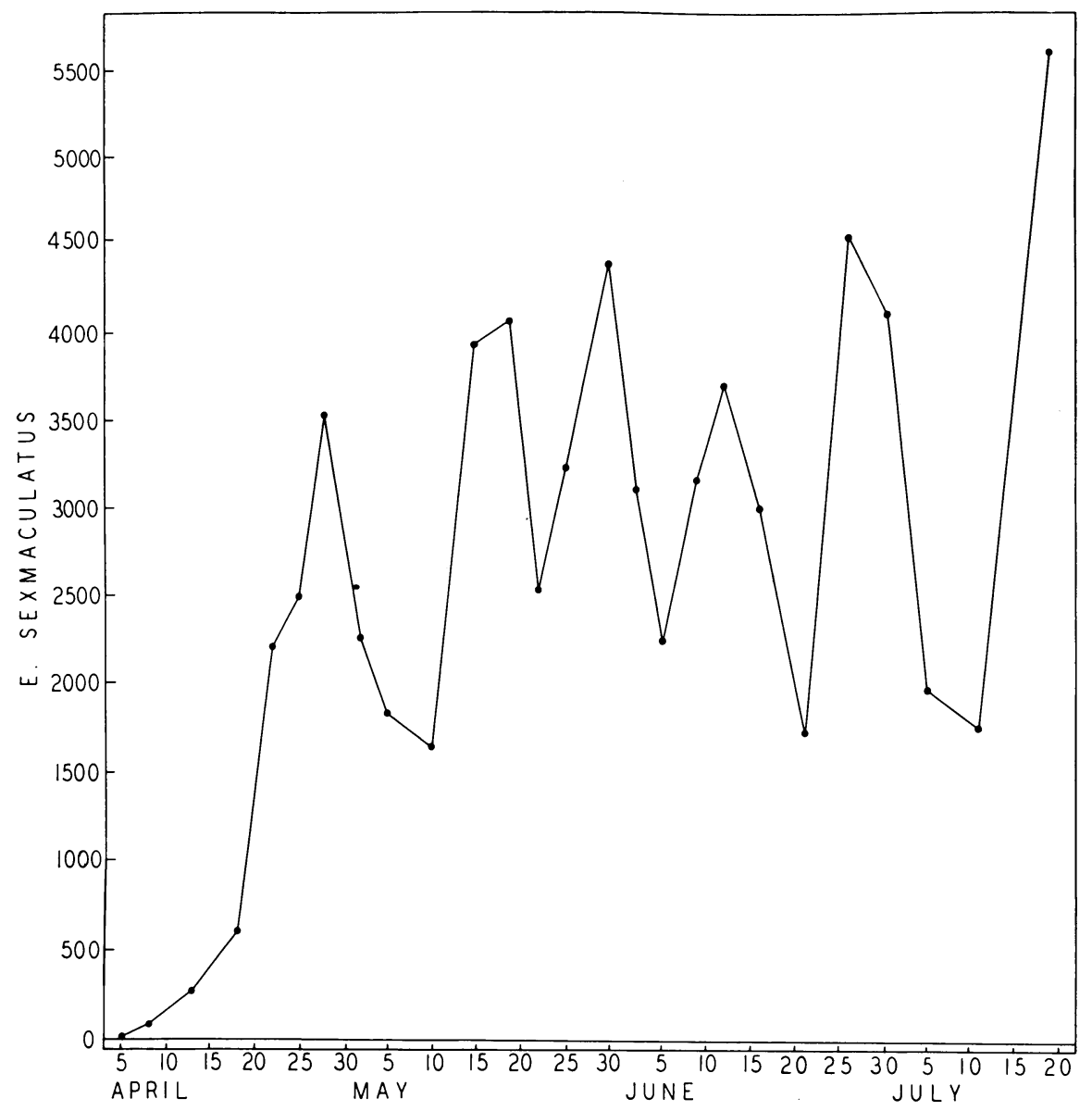

Fig. 7. Densities per orange-area of Eotetranychus sexmaculatus in the absence of predators, with four large areas of food (orange surface) widely dispersed among 36 foodless positions-a 2-orange feeding area on a 4-orange dispersion (see fig. 4 and text, Subsection B, Section I of "Results").

colonization of each new orange added, and thus little loss of time in utilization of the food was occasioned. Also, even after such prompt conditioning, the oranges continued to support for some time a much reduced but sizeable population of mites, and these factors support the position that in this universe the more complete utilization accounted for the higher mean level of density, comparing this universe with those of Subsections B, figure 7, and C, figure 8 , of this section.

B. Predators Absent, Four Large Areas of Food Widely Dispersed. In this universe, as in the last, a 2-orange feeding area on a 4-orange dispersion was employed (in this case, not grouped), and the unit was started on April 5 and ended July 18 (see figs. 4 and 7).

The mean level of density of $E$. sexmaculatus subsequent to the initial period prior to May 20 was 7,000 , or 3,500 per orange-area. It is seen, there- 


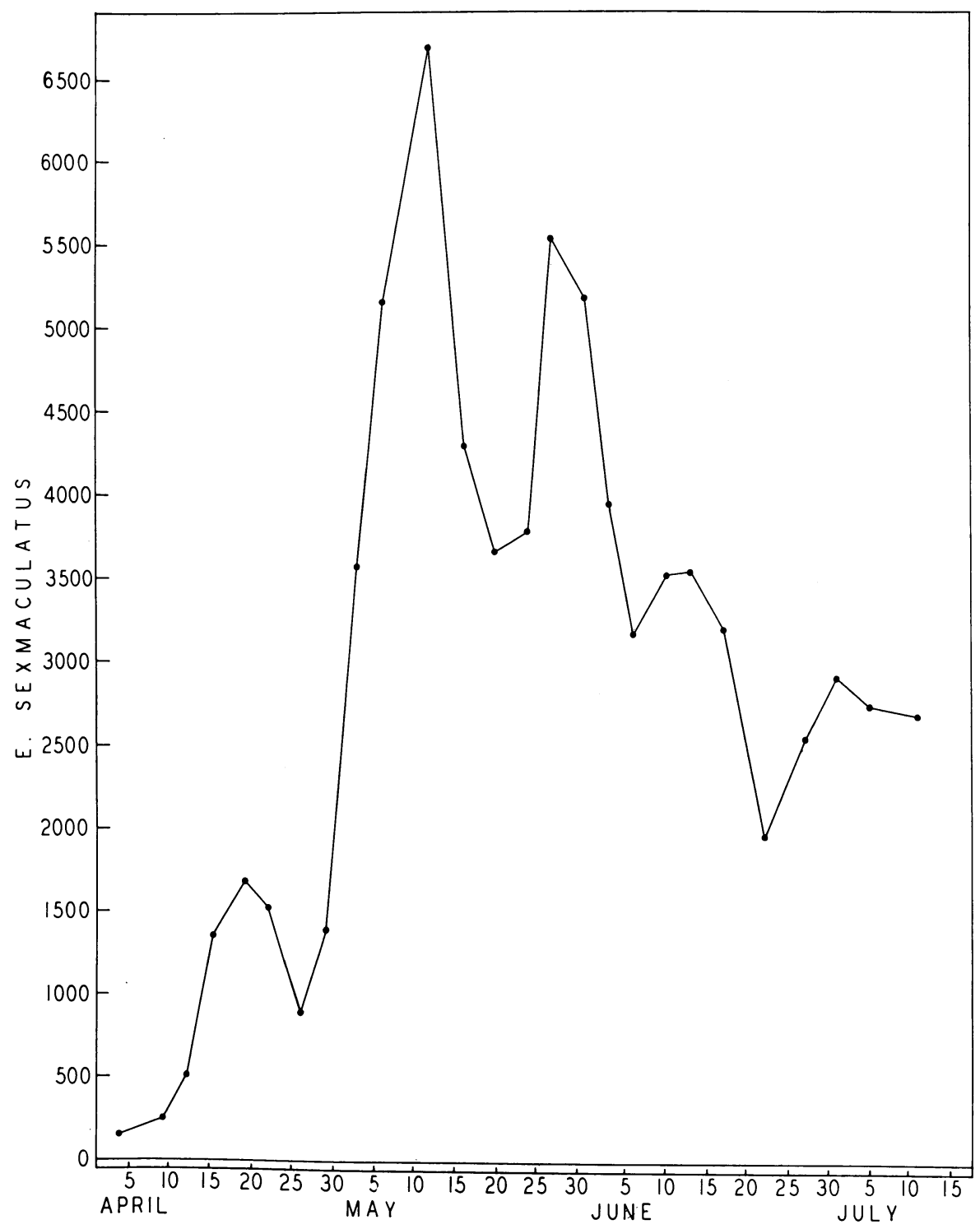

Fig. 8. Densities per orange-area of Eotetranychus sexmaculatus in the absence of predators with 20 small areas of food alternating with 20 foodless positions occupied by rubber balls-a 2-orange feeding area on a 20-orange dispersion (no photograph of this exact arrangement, but see text, Subsection C, Section I of "Results"). 
fore, that although the same quantity of food was supplied, the utilization was somewhat lower due to the difficulty the mites had in quickly locating the new orange units and the resulting loss in population in doing so, with reduced utilization during the time the oranges were in the universe.

There was also a different pattern of fluctuation in numbers, the changes being somewhat more regular in occurrence, and less marked maxima exhibited, than was so when the four oranges were placed adjacent and joined at one arena in the universe. The interaction between the difficulty of dispersal and the supply of food appears to have had a slightly stabilizing effect, compared with the condition when the supply of food alone was the primary feature and problems of dispersal minimal in effects. Unquestionably, the known variation in the quality of the oranges used is a source of error-but doubtfully sufficient to nullify this indication.

Tracing this population, 20 female mites were placed on a single orange and the population growth occurred almost entirely on the single originally stocked orange until just prior to April 28 at which time conditioning of that orange had forced migrants to search for food. By May 2 they had located the other three oranges, but not in sufficient numbers to forestall the decline in the general population resulting from conditioning of the orange originally stocked. The second ascent followed an expected course and was also short-circuited by conditioning on one of the first naturally colonized oranges on which the population first got well under way, at a time before the numbers which had located the other two oranges had increased enough to offset the decline. Subsequent events were similar; the distances between positions with food, and the difficulty the mites had in locating them were such that usually only one orange was highly productive at a time and occasionally an orange came due for removal prior to full utilization. However, none was removed which harbored a major portion of the total population. This would account for the mean density being somewhat lower than that which was experienced in the universe of Subsection A, figure 6, of this section, in which relatively full utilization was experienced.

Unusually high levels of density were the result of a partial chance occurrence of simultaneous productivity on two or more of the four oranges, but the resultant steep ascents such as those occurring during the last half of June and again between July 12 and July 18 are certain to be followed swiftly by corresponding declines in density.

C. Predators Absent, 20 Small Areas of Food Alternating with 20 Positions with No Food. In this universe, also, a 2-orange feeding area was employed, but this was segmented into 20 parts of $1 / 10$ orange-area each, with one part on each of 20 oranges. The 20 oranges were placed in alternate positions with 20 rubber balls. The universe was started on March 31 and ended on July 11, but the first count was made on April 4 (see fig. 8).

It should be noted that although the food material was segmented into 20 parts and dispersed over 20 oranges (equalizing to a much greater degree the variation in orange quality) and 20 positions in the universe, each orange was only one position distant from another and the positions having no food (the rubber balls) were much fewer in number. Consequently, although the food was widely dispersed it was readily accessible and sources of migrants 
were close at hand to any new orange added. In this respect the unit more nearly resembled those universes in which all the food was massed at one arena in the universe and on adjacent oranges.

The mean level of density of mites subsequent to the initiation period prior to May 20 was 6,600 , or 3,300 per orange-area. This is slightly lower than the results of the previously discussed universe. It is likely that the differences in the actual levels of the means in these last two instances do not have real meaning, but the patterns of change in density are probably meaningful of an inherent relation to the types of dispersion employed. Yet, if the initial extreme high in density, occurring during the middle of May, is included, the mean level would be approximately 3,800 per orange-areastill somewhat below the mean level of the universe in which the oranges were grouped and joined (fig. 6), but slightly higher than that exhibited in the universe just discussed.

Tracing the history of this population, it was initiated by placing 10 female $E$. sexmaculatus on each of two of the 20 oranges. The first count on April 4 showed a mean population of 152 per orange-area, and these were still located only on the two colonized, or stocked, oranges. Not until April 19, at which time the population on these two oranges was first noted as causing conditioning and under competitive pressure, had migrants generally moved to other oranges; only one other orange had a few mites prior to that time. That date also marked the decline of the population, and this decline was due to the conditioning on the two oranges stocked originally, before the other 18 oranges had been located and population growth on them gotten under way. In this universe nearly all the oranges were found at this same initial period of migrants and the subsequent very steep population increase was the result of simultaneous utilization of the unused oranges in the entire universe. The second depression in the middle of May was due to rather general conditioning of many of those oranges, and the next increase was made possible by the replacement of utilized oranges by new ones according to the predetermined schedule.

There was in this case a strong indication that the period of initiation and establishment of a balance between density and the schedule of supplying food is prolonged much beyond a period of 45 days. The large amplitude of fluctuations in the early stages of the experiment, considered in relation to the successive steady decrease in this amplitude, and in view of the much reduced probable source of error associated with variations in orange quality, makes it likely that a position around 5,500, or 2,750 mites per orange-area, is nearer to a true equilibrium, and that the wide fluctuations and high densities which persisted during the early course of the experiment were adjustments prior to establishment of a semblance of such balance.

In contrast to this, the data illustrated in figure 7 probably represent a meaningful difference in patterns of population change. In that case the large fluctuations did not diminish with time. In the universe illustrated in figure 7, a position with food is found with great difficulty, but each such position has a supply five-fold in quantity. In the present example, figure 8 , there are five times as many positions with food, but each has only $1 / 5$ the quantity. The positions with food are more readily located but each is de- 
pleted more rapidly. Additional replicates would need to be run and continued over a longer period of time in order to answer the questions raised.

\section{Population Changes under Predator and Prey Interactions}

A. Predators Present, Simplest Universe, Four Large Areas of Food, Grouped at Adjacent Joined Positions. In this universe a 2-orange feeding area on a 4-orange dispersion was employed. The unit was started February 4 by stocking with 20 female six-spotted mites. It ended April 5 (fig. 9). The

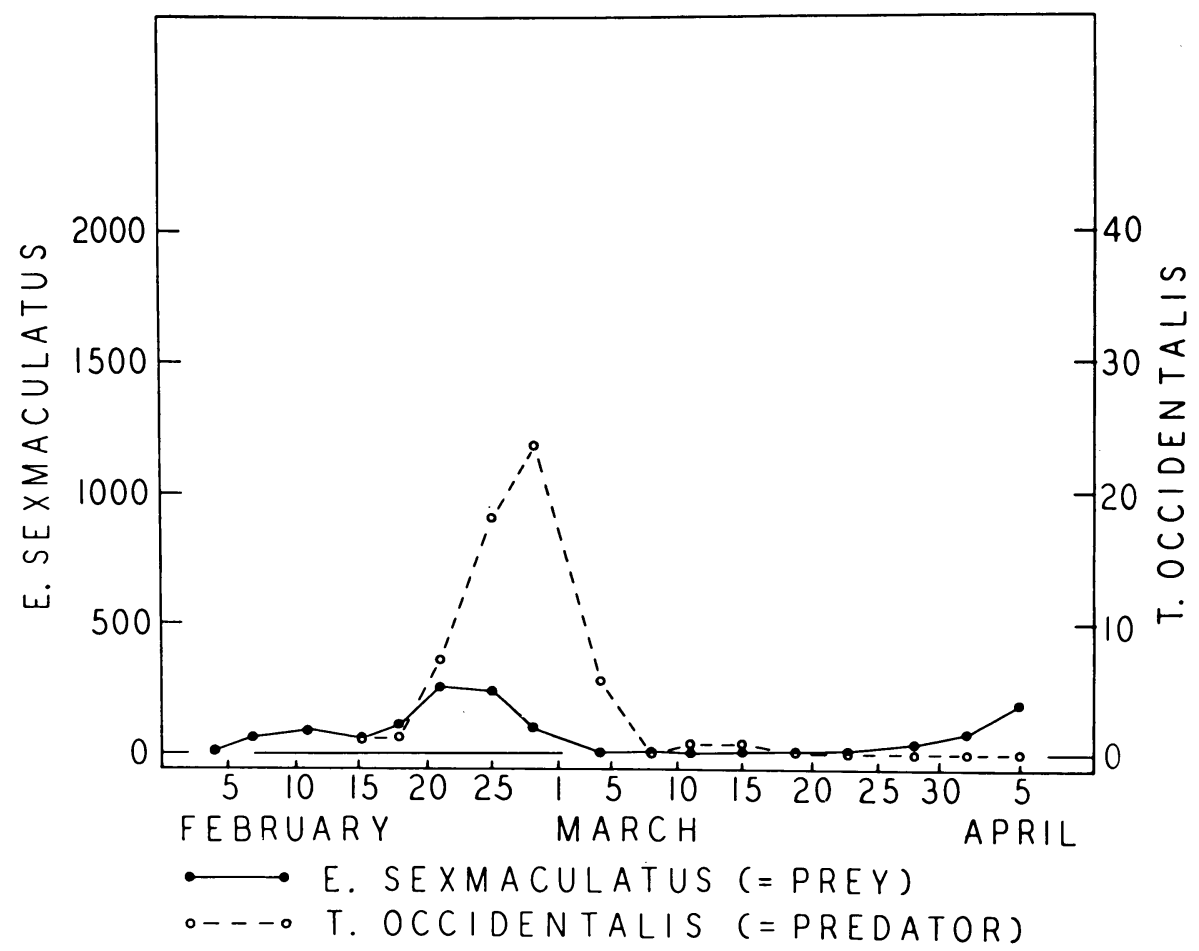

Fig. 9. Densities per orange-area of the prey, Eotetranychus sexmaculatus, and the predator, Typhlodromus occidentalis, with 4 large areas of food for the prey (orange surface) grouped at adjacent, joined positions-a 2-orange feeding area on a 4-orange dispersion (see fig. 3 and text, Subsection A, Section II of "Results").

arrangement was the same as the control universe of Subjection A of Section I (see also figs. 3 and 6 ) except that in this universe the predatory species was present. Two female predators were introduced 11 days after the introduction of the six-spotted mites. Both predators were placed on a single orange. This scheme was followed with all the universes except as otherwise stated.

The stocked orange spoiled between February 7 and February 11, and, consequently, the prey then declined in numbers and only increased after moving to the adjacent oranges. The prey then increased to a level of 500, 


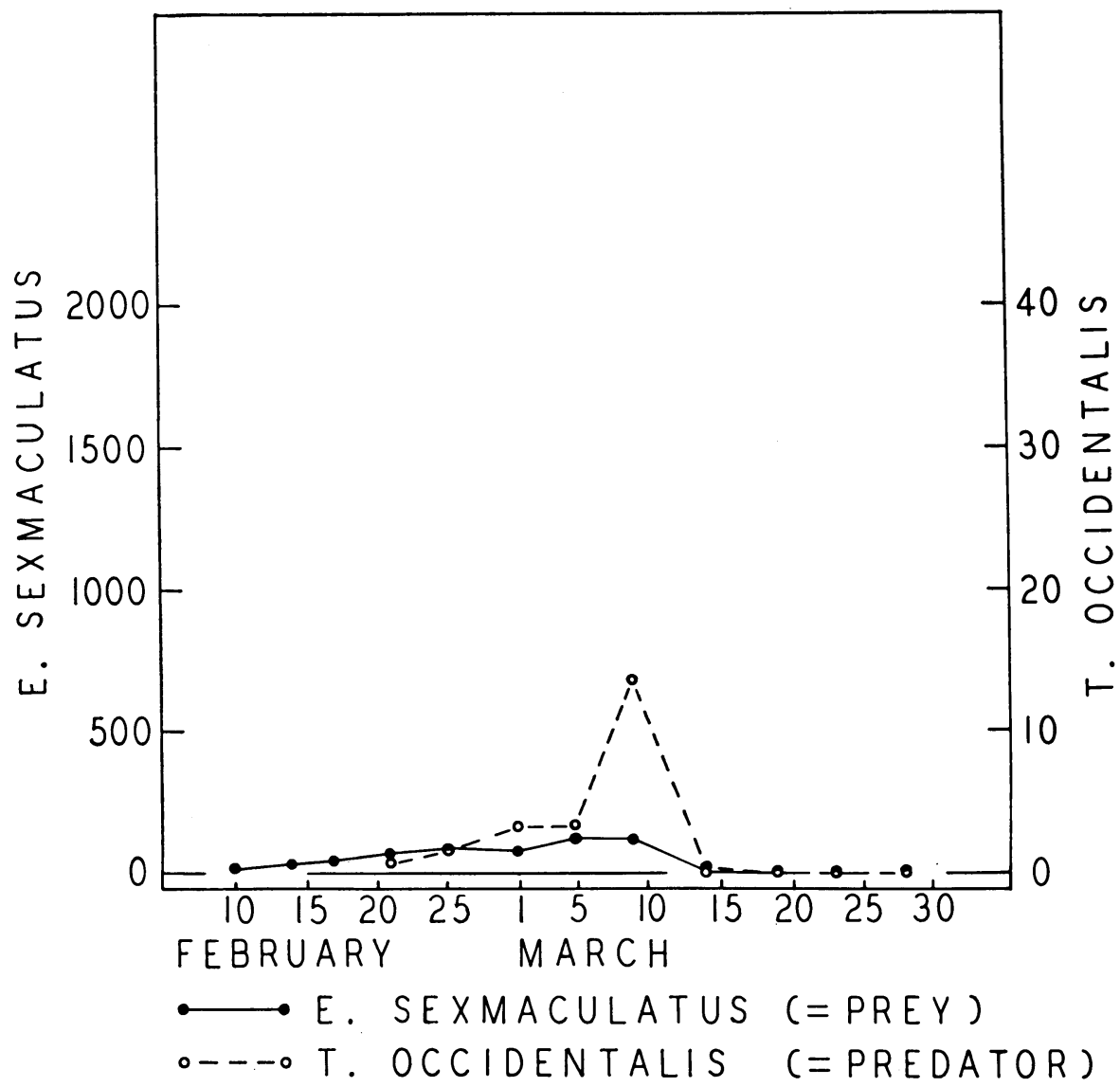

Fig. 10. Densities per orange-area of the prey, Eotetranychus sexmaculatus, and the predator, Typhlodromus occidentalis, with 8 large areas of food for the prey (orange surface) grouped at adjacent, joined positions-a 4-orange feeding area on an 8-orange dispersion (no photograph of this exact arrangement, but it was similar to that of figure 3 except that 8 oranges were used; see also text, Subsection B, Section II of "Results").

or 250 per orange-area, at which time it was preyed upon so severely that it was reduced to a nil density within 10 days and all the predators subsequently starved. The consequent characteristic, very gradual increase in the numbers of the prey was then prolonged for about 15 days before there was attained a state of vigorous population growth (see "Discussion").

B. Predators Present, Eight Large Areas of Food, Grouped at Adjacent Joined Positions. In this universe a 4-orange feeding area on an 8-orange dispersion was employed, and the unit was started February 10 and ended March 28 (fig. 10). The eight oranges were grouped in one end of the tray and joined with wire loops. In this case, because of the larger quantity of food supplied, 40 female six-spotted mites, or prey, were colonized initially, 20 on each of two of the eight oranges. Two female predators were added 11 days later. 
The notes taken during the early days of this universe reveal that the female six-spotted mites used for colonizing were old and not from the usual stock colony of vigorous young females. These females died quickly without producing the usual quota of eggs after colonizing. Hence, the population could not increase at the usual rate until the first daughters became fecund. By the time that occurred and the normal population increase would other-

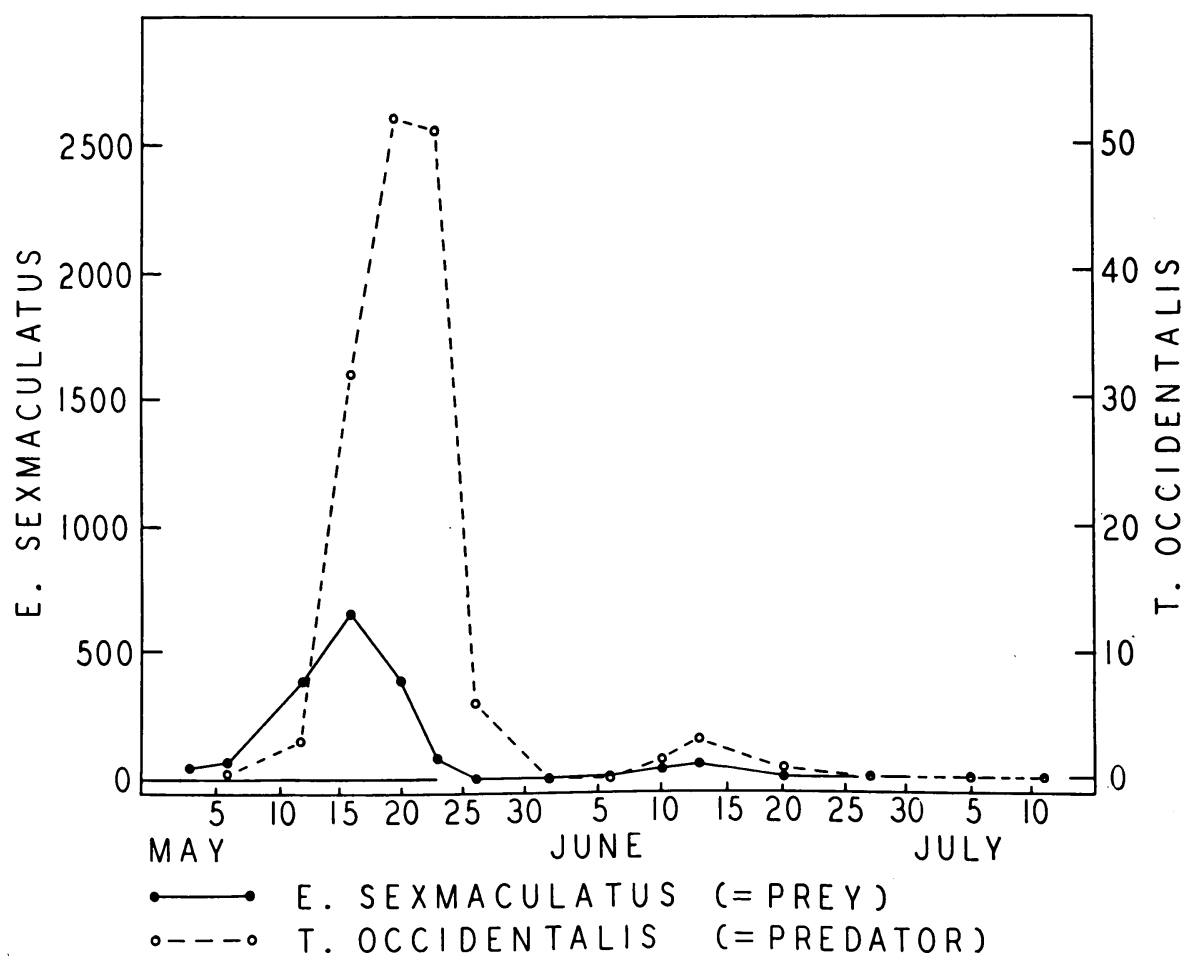

Fig. 11. Densities per orange-area of the prey, Eotetranychus sexmaculatus, and the predator, Typhlodromus occidentalis, with 6 large areas of food for the prey (orange surface) grouped at adjacent joined positions-a 6-orange feeding area on a 6-orange dispersion (no photograph of this exact arrangement, but it was similar to that of figure 3 except that 6 whole oranges were used; see text, Subsection C, Section II of "Results").

wise have ensued, the predators had become sufficiently abundant that the increase never occurred at all, even though migrants had moved to and populated at least six of the eight oranges. Hence, the population reached a maximal level of only 451 mites, or 113 per orange-area.

In this universe the predators overexploited the prey by March 14 to the extent that not only did they annihilate themselves but they also annihilated the prey species, even though the latter had dispersed successfully throughout the universe.

C. Predators Present, Six Whole Oranges as Food, Grouped at Adjacent Joined Positions. In this universe a 6 -orange feeding area on a 6-orange dispersion was employed. The unit was started with 20 female six-spotted mites 
on April 26 and ended July 11 (fig. 11). The prey were introduced on two oranges, the two female predators on only one of them.

The prey temporarily thus escaped severe predator action on one of the oranges and a few migrants moved onto some of the other oranges, but this was not until about May 15, and before these were able to effect an appreci-

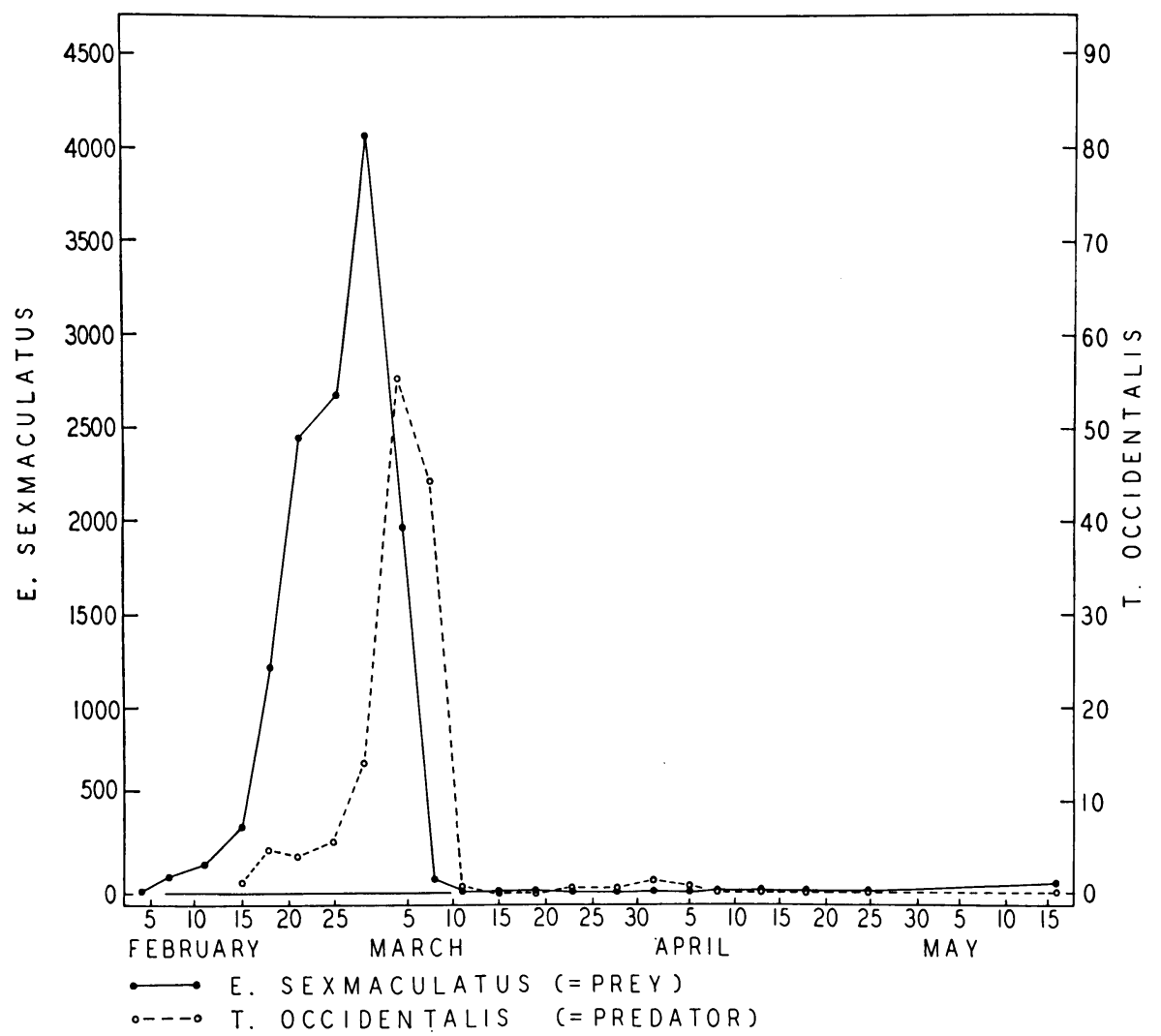

Fig. 12. Densities per orange-area of the prey, Eotetranychus sexmaculatus, and the predator, Typhlodromus occidentalis, with 4 large areas of food for the prey (orange surface) widely dispersed among 36 foodless positions-a 2-orange feeding area on a 4-orange dispersion (see fig. 4 and text, Subsection D, Section II of "Results").

able general population growth, the predators reached all the infested oranges. The peak population reached was 3,900 mites, or 650 per orangearea. After May 18 to 20, the prey suffered the characteristic crash effect. Contrary to what happened in most similar universes, there was limited temporary survival of the prey and the predator species. The prey increased very slightly from June 5 to June 13, and this was followed by a corresponding increase in the predators, after which time the predators quickly annihilated their prey and thus themselves.

D. Predators Present, Four Large Areas of Food Widely Dispersed. In this universe a 2-orange feeding area on a 4-orange dispersion was used (see figs. 4 and 12). The oranges were placed at randomized positions among 
rubber balls as shown in figure 4. Twenty female six-spotted mites were colonized on one orange on February 4, and two female predators were put on the same orange on February 11. The universe was ended May 17.

The wide dispersal of the food among the 40 positions presented an obstacle to movement of both the prey and the predators. In fact, neither species reached the unstocked oranges until March 28 when both did and, thus, densities on the other oranges were never substantial. The colonized orange was

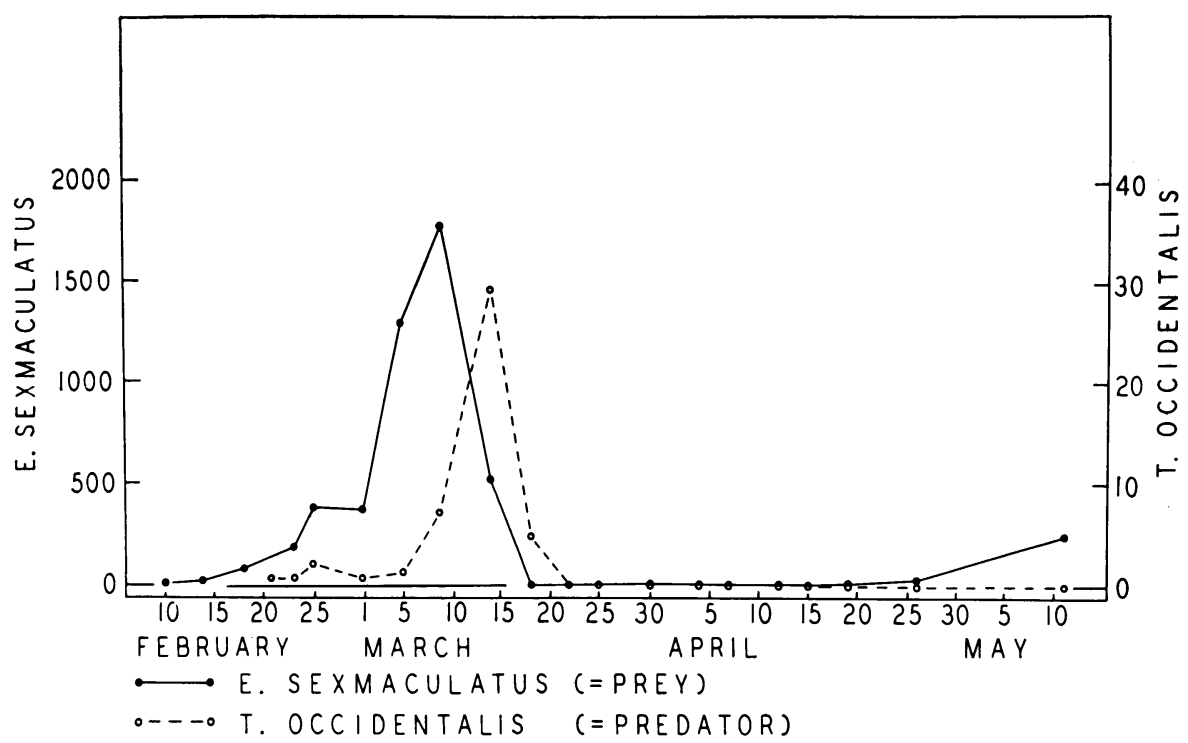

Fig. 13. Densities per orange-area of the prey, Eotetranychus sexmaculatus, and the predator, Typhlodromus occidentalis, with 8 large areas of food for the prey (orange surface) widely dispersed among 32 foodless positions-a 4-orange feeding area on an 8 orange dispersion (no photograph of this arrangement, but it was similar to that of figure 4 except that 8 oranges were used; see also text, Subsection E, Section II of "Results").

apparently phenomenal in nutritional quality for on it the prey reproduced at a very high rate, so much so that the predators did not quickly overtake it even though the latter were present on that orange from the eleventh day. The population of predators did not increase rapidly at first, although at the low density at that time it is probable that the numbers missed in the counting may have been enough to explain a part or most of this retarded increase in the midst of an abundance of prey.

At any rate, the prey population reached the high level of 8,113 , or 4,056 per orange-area. This level could not be maintained on the single orange longer than a few days even in the absence of predation; thus, both conditioning of that orange and intense predation jointly accounted for the very abrupt crash which followed. Nearly all the predators then starved but a very few survived and prevented any resurgence of the prey until after April 8 at which time the last predator died and the prey began a very gradual increase in numbers (see "Discussion").

E. Predators Present, Eight Large Areas of Food Widely Dispersed. In 


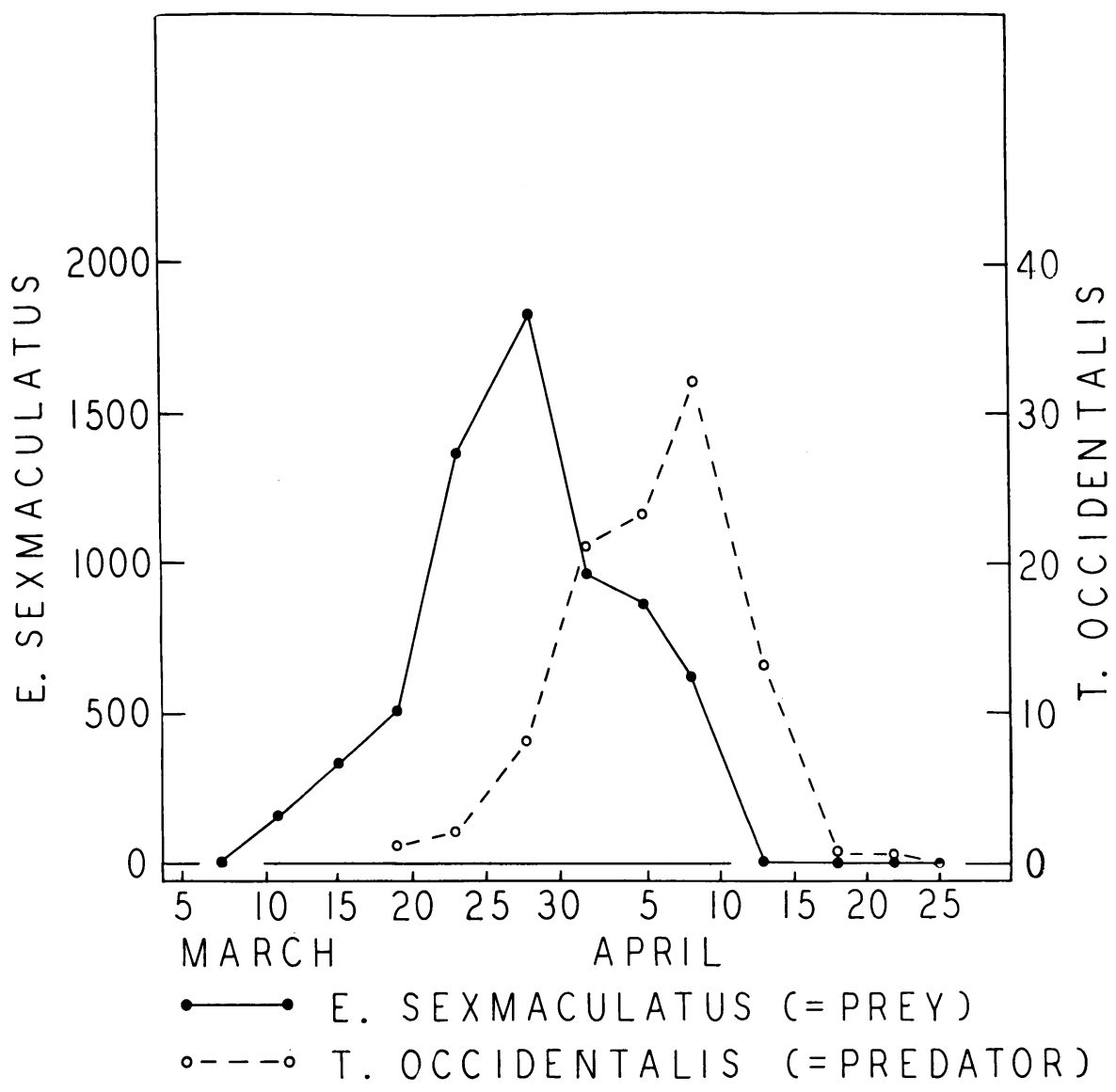

Fig. 14. Densities per orange-area of the prey, Eotetranychus sexmaculatus, and the predator, Typhlodromus occidentalis, with 20 small areas of food for the prey (orange surface) alternating with 20 foodless positions-a 2-orange feeding area on a 20 -orange dispersion (no photograph of this exact arrangement, but see text, Subsection F, Section II of "Results").

this universe a 4-orange feeding area on an 8-orange dispersion was utilized, the remainder of the 40 positions being occupied by rubber balls. The unit was started February 10 and ended May 11 (fig. 13). Twenty female sixspotted mites were colonized on each of two of the eight oranges, whereas the two female predators were introduced 11 days later on one of the oranges colonized with the prey species.

There was a logical delay of about 14 days between the ascent in the prey population and the ascent in the predator population. Thus, the prey could increase unabated on the oranges which did not receive predators until such time as the latter moved onto them. The dispersed condition of the oranges made more likely such a lag in general predator action. In the examples of the universes otherwise comparable except that the food was grouped in one area and joined (figs. 9, 10, and 11), the ascents in predator densities fol. 


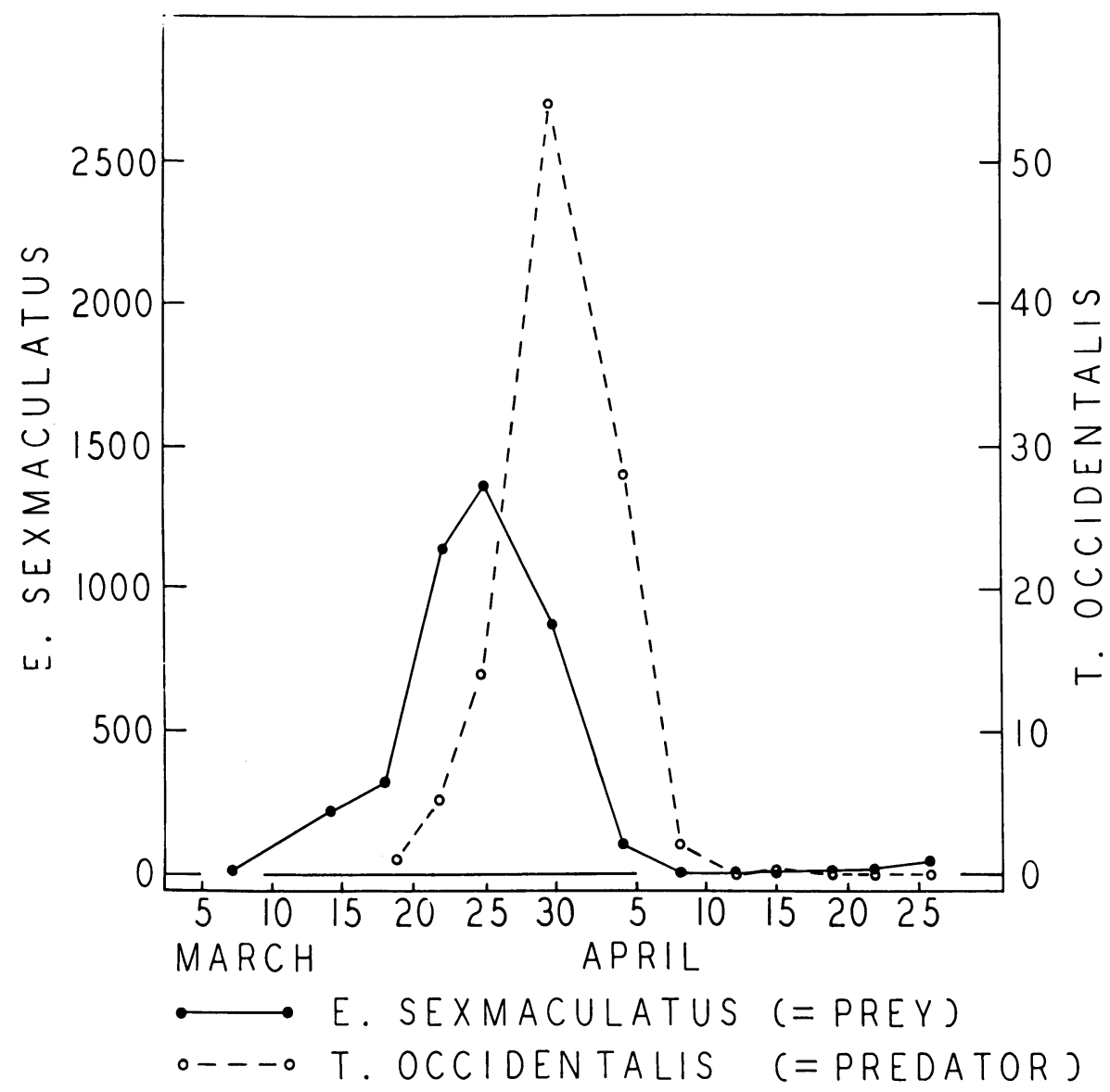

Fig. 15. Densities per orange-area of the prey, Eotetranychus sexmaculatus, and the predator, Typhlodromus occidentalis, with 20 small areas of food for the prey (orange surface) alternating with 20 foodless positions-a 2-orange feeding area on a 20-orange dispersion (no photograph of this exact arrangement, but see text, Subsection F, Section II of "Results").

lowed the respective ascents in prey densities within intervals of two or three days. Also, in those universes the prey never reached such high levels.

The lag period in this universe was sufficient for the general prey population to reach a level of 7,046, or 1,761 per orange-area before the predators moved through the universe and reduced the prey to a very low level, after which all the predators starved. The very gradual subsequent increase in the numbers of the prey up to May 25 is obvious in figure 13. After that date the undercrowding effects from the intense predator action had been overcome and a substantial increase followed.

F. Predators Present, 20 Small Areas of Food Alternating with 20 Foodless Positions. Two universes of this arrangement were used. In each, a 2-orange feeding area on a 20-orange dispersion was used and both were started on March 7. One was ended on April 25, the other on April 26 (figs. 


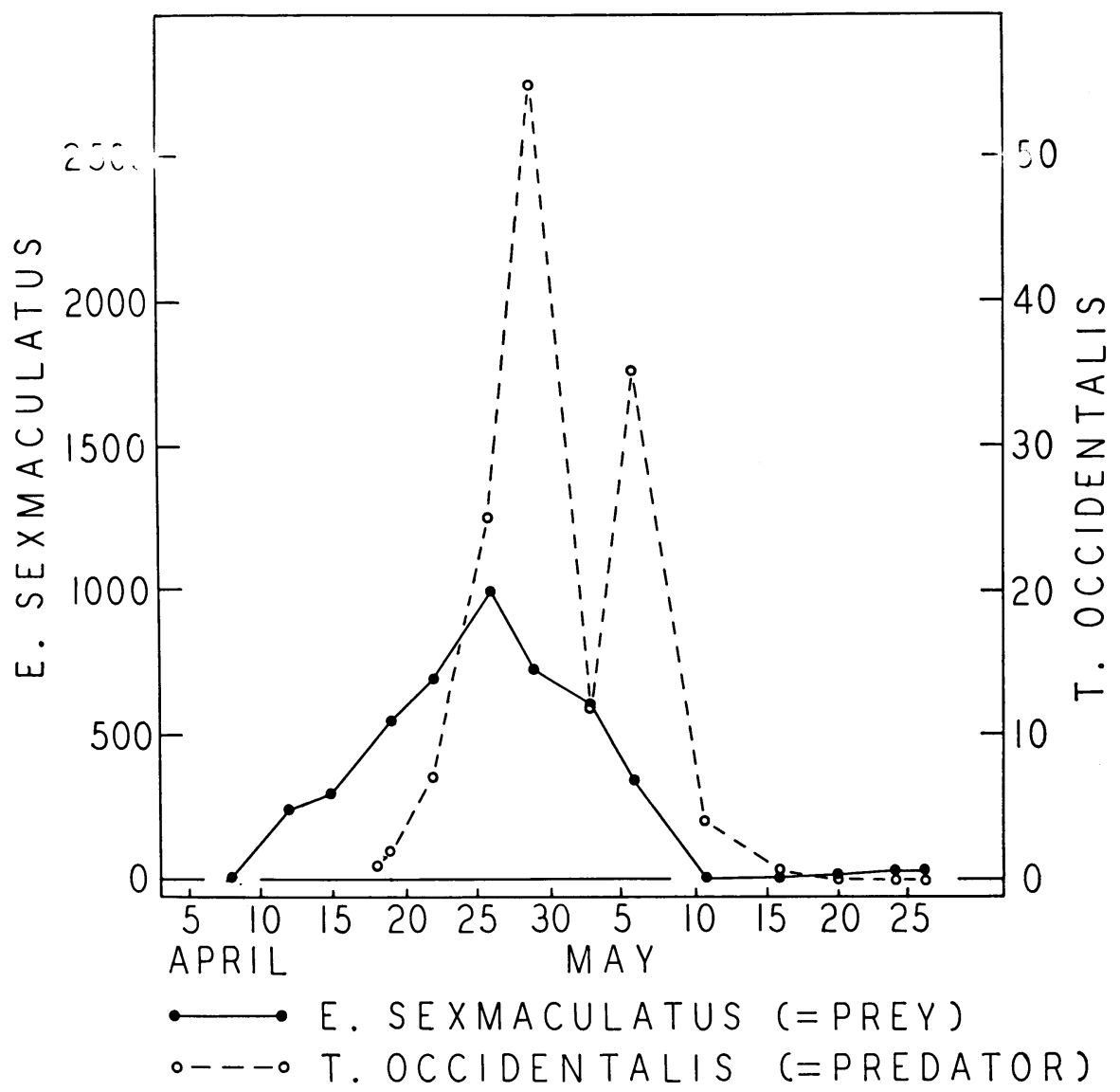

Fig. 16. Densities per orange-area of the prey, Eotetranychus sexmaculatus, and the predator, Typhlodromus occidentalis, with 40 small areas of food for the prey (orange surface) occupying all 40 positions-a 2-orange feeding area on a 40-orange dispersion, but with units of food thus adjacent (no photograph of this exact arrangement, but it was similar to $1 / 3$ of the universe shown in figure 5 except that the wooden posts were not used and the maze of vaseline partial-barriers was much less complex; see also text, Subsection G, Section II of "Results").

14 and 15). In each universe, 10 female six-spotted mites were introduced onto each of two of the oranges, and in each, two female predators were introduced onto one of the two oranges 11 days later.

In these universes the feeding area employed on a given orange was reduced to a $1 / 10^{-o r a n g e}$ area. Large areas support the prey species for long periods of time. Dispersal pressure, or overpopulation - which is now known to cause practically all movement from orange to orange-is delayed. It was felt that by decreasing the feeding surface at each orange position-thus having more positions-the prey would be kept on the move from more individual sources so that following a localized crash from predation, there would occur sooner a subsequent population pressure which would cause more 
rapid dispersal and resultant repopulation on a broader spatial basis in the universe. This seemed to offer a better possibility for achieving perpetuation of the predators and prey than would wider dispersion of the smaller number of larger areas of food.

With one of the examples, the period of lag in the increase in predators was just as long, and, with the other, it was three to four days shorter than it was for the units just previously discussed. However, the prey populations did not reach levels quite so high. The higher level, however, occurred in the universe where there was the longer period of lag in the predator response to prey increase (see fig. 14). In this universe the predators exterminated the prey by April 18 and then died themselves. In the other example (see fig. 15), the prey was almost, but not entirely, exterminated by April 8. The predators quickly starved after that date and subsequently the prey gradually increased in numbers. Thus, even when 20 positions of food were used, the prey was exterminated in one instance although it survived in the other (see "Discussion").

\section{G. Predators Present, 40 Small Areas of Food Occupying All Positions.} In this universe a 2-orange area was again utilized, but the feeding area on each orange was further reduced to $1 / 20$-orange area ; thus, all 40 positions were occupied by oranges (a 40-orange dispersion)-i.e., no rubber balls were used. The unit was started April 8 and ended May 26 (fig. 16). Ten female six-spotted mites were colonized on each of two of the oranges and 10 days later two female predators were colonized on one of them.

The tray used was also divided into three areas, mostly, but not entirely, separated by vaseline barriers as an impediment but not an exclusion to movement. The barrier pattern was not as complicated as that used in the later experiments such as those shown in figure 19. It was felt that the presence of the barriers would introduce greater difficulty for the predators in contacting all general positions of prey at a time, and the smaller areas of food would insure quicker movement of the prey and repopulation of depopulated areas by migrants from areas missed at the time of greatest predator abundance and pressure.

Subsequent to the expected initial increase, there was a sharp decline in the predators between April 29 and May 3 to a level below that which could be supported by the prey population in the total universe at the time. There was then a second sharp increase in the predators as they moved into one of the areas where they had not previously made contact with the prey. The second decline in predators and prey was general throughout the universe and the predators then starved since the prey reached a level which would not support a single predator. The prey population then began a gradual increase in numbers.

In this universe it became obvious that the history of events could not be properly illustrated by use of a simple line graph plotting densities, and this became increasingly true when still greater complexity was introduced. The counts made on the individual oranges revealed, unquestionably, that the sharp drop in predator abundance between April 29 and May 3, and the immediately subsequent sharp increase in numbers, were reliable reflections of the changes in the total populations in the universe. Only a pictorial record 


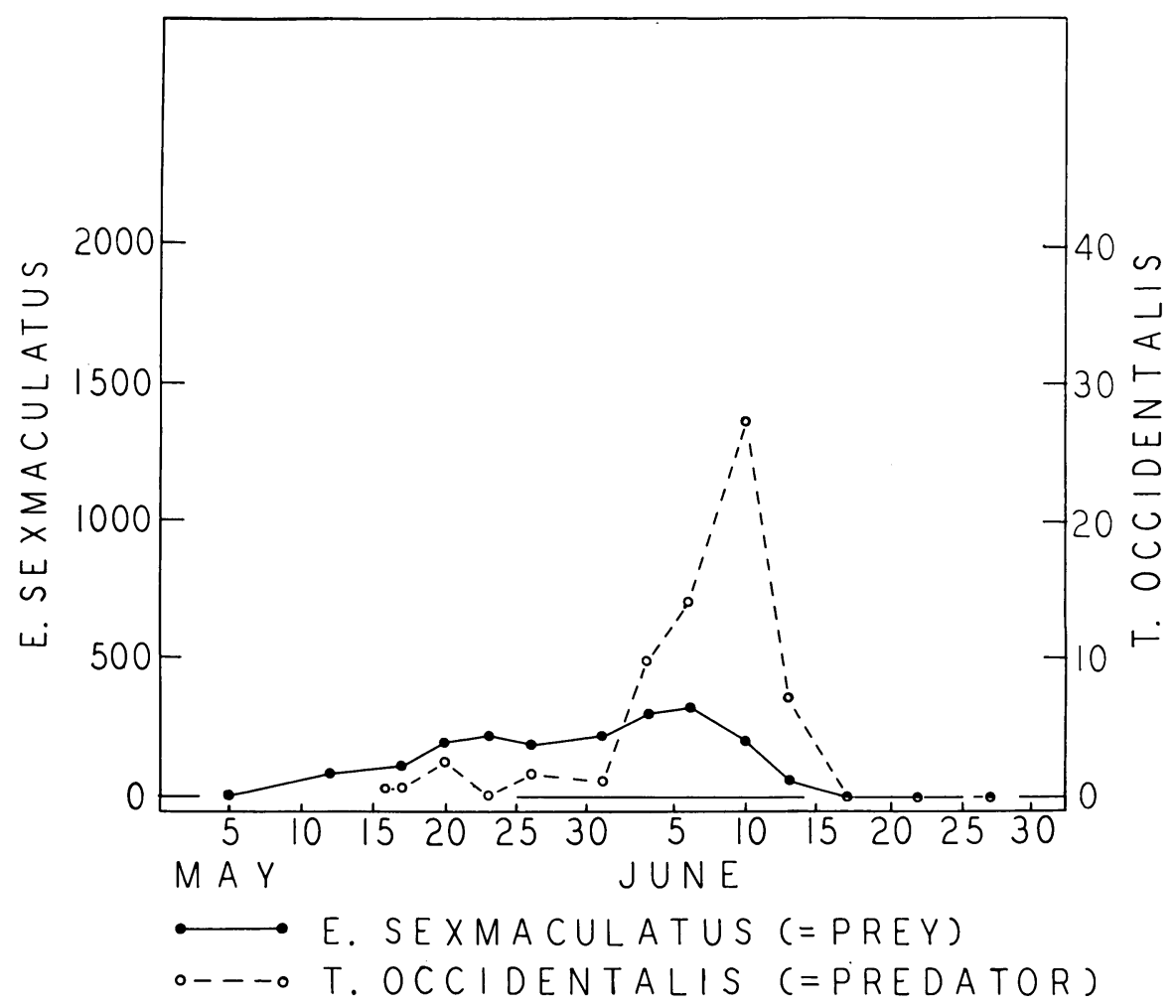

Fig. 17. Densities per orange-area of the prey, Eotetranychus sexmaculatus, and the predator, Typhlodromus occidentalis, with 120 small areas of food for the prey (orange surface) occupying all 120 positions in a 3 -tray universe-a 6-orange feeding area on a 120-orange dispersion, with a simple maze of vaseline partial-barriers utilized (no wooden posts), but with the stocking done in a very restricted manner (see fig. 5 and text, Subsection H, Section II of "Results").

of the densities of the predators and the prey in the specific geographic areas in which the predators were active, and in which they were not active, could be expected accurately to portray the situation. Otherwise, the data reveal a sharp decline in predators, followed by a rapid increase, and then followed again by a rapid decline-all taking place synchronously with a rather steady general decline in density of the prey, if the data for the whole universe are plotted as a single unit as in figure 16.

Such events are contrary to the known fact of specific dependence of this predator upon this prey in these universes and, as well, contrary to the fact of the predator's rapid response to changes in the numbers of its prey by corresponding changes in its own numbers if it contacts its prey. Such a pictorial record was constructed for the data of the most important of these experiments (see fig. 18), but the time required to do this for each universe would be excessive. In any event, this does not appear to be necessary when simple universes are used (see "Discussion"). 


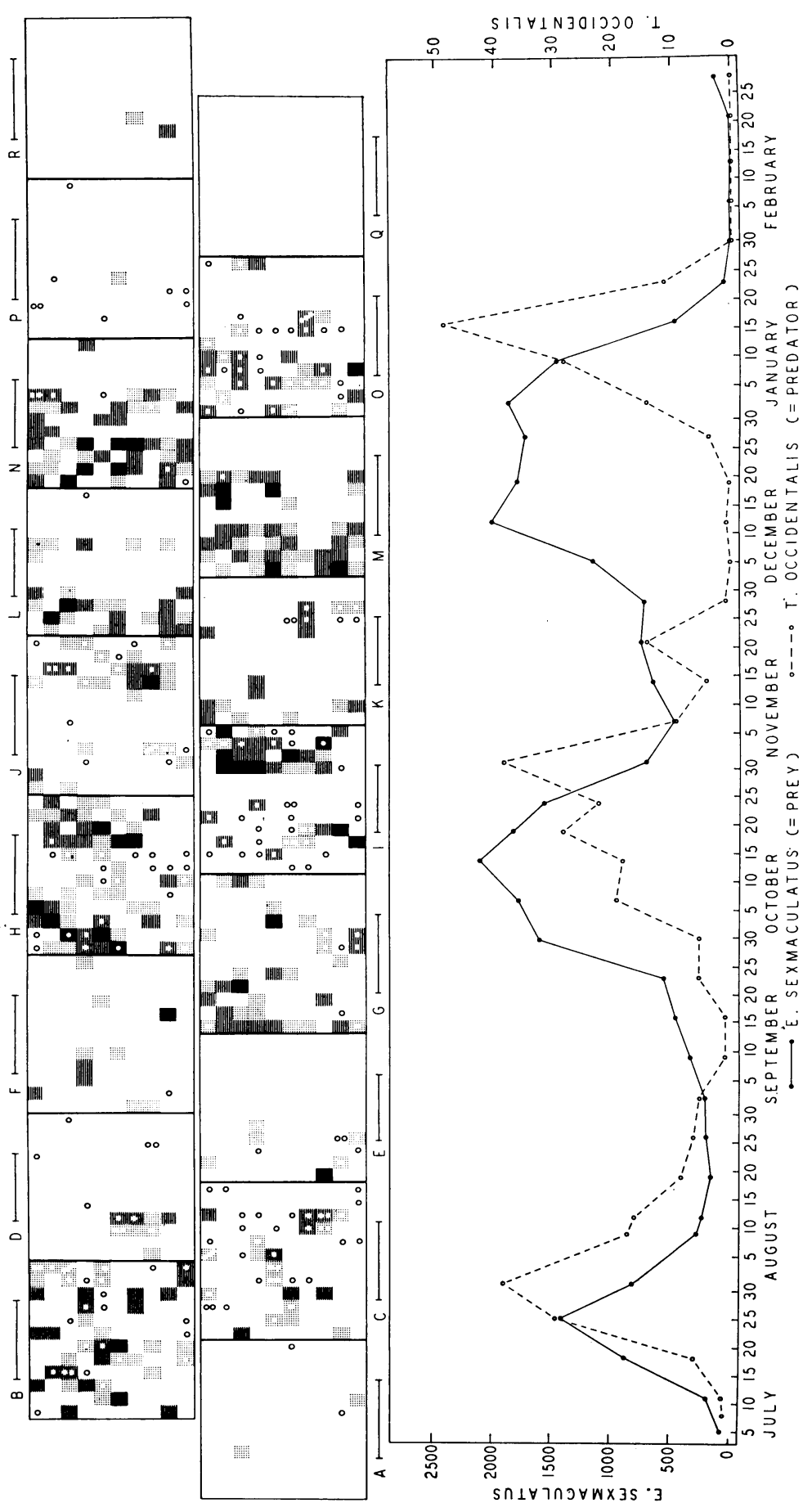

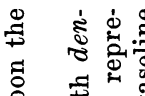

总葍雾

क क छ

क

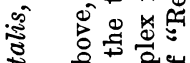

क 등명

คํํำ

요윰 영

4 से

㐘军 宅

वै के

क्षे का

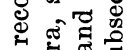

蛋

웡

: $=50$

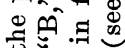

क.

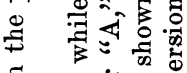

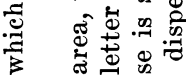

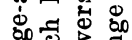

휴

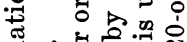

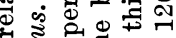

농 क्ष

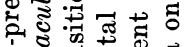

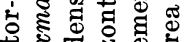

西 4 \%

क्ष

مै ญ

๘

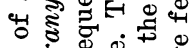

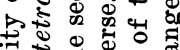

可䓃.

क्ष

I

.

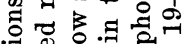

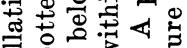

雨

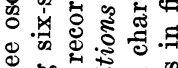

입.

स :

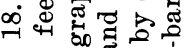

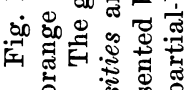


H. Predators Present, 120 Small Areas of Food Occupying All 120 Positions, a 6-Orange Area. In this universe the area of orange exposed at a position was the same as that used in the universe just discussed and the food occupied all positions (no rubber balls were used), but the need for an increase in the total potentials and complexity had become obvious. Hence, in this unit, the food potential and the total areas required to be covered in searching were trebled, i.e., a 6-orange area was used on a 120-orange dispersion. The universe consisted of three of the trays (previously used singly) joined together (see fig. 5). An arrangement of vaseline partial-barriers was again used (see fig. 19). The universe was started with 10 female six-spotted

\begin{tabular}{|c|c|c|c|c|c|c|c|c|c|}
\hline 1 & 2 & 3 & 4 & 5 & 6 & 7 & 8 & 9 & 10 \\
\hline 11 & 12 & 13 & 14 & 15 & 16 & 17 & 18 & 19 & 20 \\
\hline 21 & 22 & 23 & 24 & 25 & 26 & 27 & 28 & 29 & 30 \\
\hline 31 & 32 & 33 & 34 & 35 & 36 & 37 & 38 & 39 & 40 \\
\hline
\end{tabular}

Fig. 19. Diagram of a tray used in the complex 3-tray universes (see figs. 17 and 18) with the positions of vaseline barriers shown by black lines.

mites, placed on each of two oranges in one of the trays on May 5. Two female predators were added on one of these oranges on May 16. The universe was ended June 27 (fig. 17).

In this universe the predator action was again delayed. However, movement of the prey from the one tray in which the initial colonies of both species were introduced never occurred, and it thus became obvious that with the use of such universes a wider arbitrary spread of the initial stock should be employed. Otherwise, the data of this universe added nothing new.

I. Predator-Prey Oscillations, 120 Small Areas of Food Occupying all 120 Positions, a 6-orange Area. This universe was basically like that of the last discussed but greater complexity and a different scheme of introducing the initial colonizing stock were employed. The universe was a three-tray arrangement, and a 6-orange feeding area on a 120-orange dispersion was again used. The partial barriers of vaseline were also used (see fig. 19). Contrary to previous procedure, 120 female six-spotted mites were introduced on June 30 (the graph of fig. 18 shows the first count date, July 5). That is, one mite was placed on each of the 120 oranges. In this universe also, the predators were added only five days later so as to permit them to become effective prior to general conditioning of the stocked oranges by the prey. Also contrary to the previous procedure, 27 female predators were introduced, and these were distributed, one on each of 27 oranges, these being 
representative of all major sections of the universe. This scheme assured that the populations would not become annihilated prior to dispersal to all parts of the universe-such as happened in the unit previously discussed. This experiment was ended March 27, although because of engraving difficulties, the data were plotted only to February 28 (see fig. 18).

In addition, small wooden posts were placed in upright positions in each of the major sections of the universe. This was to give the prey species a maximal opportunity to disperse over the vaseline barriers, thus utilizing its adaptive ability to drop by silken strands and be carried by air currents to new locations. An electric fan was used to create a mild air movement in the room. Although the predators have superior dispersal ability within a limited environment where movement by wind is not involved, they do not utilize this method of movement. On the other hand, by virtue of such adaptations the prey species has very superior abilities to disperse over greater distances to entirely new areas and environments. Therefore, a restricted environment or universe of the kind used in these experiments utilizes the superior dispersal power of the predator within local areas without giving chance for expression of the equally important superior dispersal power of the prey across greater distances and obstacles. The wooden posts were introduced in an effort to partially correct this condition in these experiments. They did not prove entirely satisfactory, and a more elaborate arrangement to accomplish this purpose should be employed.

Although they were joined into a single universe, the three trays may be looked upon as adjacent microenvironments, and so may the smaller subdivisions within the trays. By this scheme the changes in various areas or the geographic waves in distribution (see charts $A$ to $R$ of fig. 18), as well as the general density changes in the whole universe were followed. It should be noted that the horizontal dimensions of these charts were reduced (relative to the vertical dimensions) because of difficulties in reproduction on a single page. The horizontal dimension of each universe was 50 inches, the dimension shown vertically was 40 inches.

It is obvious in the charts of figure 18 that the divisions between trays, although not covered with a barrier, were an impediment to movement of somewhat greater effect than that caused by the vaseline barriers used within each tray.

The charts, $A$ to $R$ of figure 18 represent a compromise with the ideal of showing the exact locations in the universe and the densities of the entire population on each date of sampling. In order to have the charts on the same page and running synchronously with the linear graphs of density on the same time scale, the data for each pair of sampling dates were combined. The horizontal lines by each letter "A," "B," "C," et cetera indicate the corresponding time period of the two dates of counting. Note that the chart for the first period, "A," is below, the second, above, the third, below, the fourth, above, et cetera. The classes of density used for the predators and for the prey were limited in number.

In some instances a few prey were present but not enough to be shown. In some instances of predators being shown in areas where no prey are shown, 
that is a true condition; in others, it may mean only that although the prey were present, there were too few to justify shading. In either instance, such rarity of the prey means that the predators there would be doomed shortly to starvation, and the charts reveal this fact. Note also that the predators are shown in such "white" areas by white circles (ringed), whereas within the shaded areas indicating prey densities, they are shown by white circles also, but no bordering rings are used.

Considering the trays individually, or any sections of the trays individually, the predators either moved away or died in every case just as was true in Gause's experiments with protozoa and with cheese mites, or has been so in all the universes previously discussed herein. However, by utilizing the large and more complex environment so as to make less likely the predators' contact with the prey at all positions at once, or essentially so, it was possible to produce three waves or oscillations in density of predators and prey. That these waves represent a direct and reciprocal predator-prey dependence is obvious.

The maximal density of prey during the first oscillation was 8,550 , or 1,425 per orange-area. The predator population responded quickly to the increase in abundance of the prey since the two species occupied the same arenas by virtue of the manual distribution in stocking of the oranges initially (see "Discussion").

The second peak density of prey occurred about October 15 and was somewhat higher than the first at 12,624, or 2,104 per orange-area. The higher level was an automatic effect of the greater lag in response by the predator population during the initial period of this oscillation-i.e., from September 10 to September 30 or somewhat beyond. This lag resulted from the predator's lack of contact with the main masses of the prey which were present in two of the three trays (left third and right third-see charts F and G, fig. 18), although they were in substantial contact with the prey of the center tray (lower center area of chart $G$ ) and slightly so with the much larger population in the left tray, or section. Thus the prey were able to sustain a marked increase in density in two of the three trays, as is shown by the progress seen from chart $\mathrm{F}$ to chart $\mathrm{H}$ and as seen in the graph for this period. More general contact with the prey was eventually achieved but the pattern of achievement reveals the reason for the rather erratic changes in density of the prey during the process (from October 7 to October 31 ). On October 7 the predators had reached a moderate density in the universe of 19 per orange-area, but most of these were located in the lower section of the middle tray (chart $\mathrm{G})$, the aftereffect of which is shown in chart $\mathrm{H}$ in the elimination of most of the prey in that area and the numbers of predators still present in that area but without food. This chart also shows that their general movement had been partly onto oranges where their prey was abundant and partly onto ones where they found little or no food. As shown in this chart, also, the predators had made substantial contact with the main mass of prey in the left tray but still had not done so in the right tray in which the prey were now rapidly increasing in numbers. It was not until later (chart I) that the right tray also was reached and general population decline of both predators 
and prey ensued. Thus, localized discontinuity in contact accounts for the zig-zag pattern of increase in the density of the predators during the period involved. A smoothed curve of densities of the predators would correspond to the usual pattern of a predator-prey relation.

During the third major increase in the population of the prey, the maximal density reached was 11,956 , or 1,993 per orange-area. In this instance, the prey had escaped substantial predation for a long period. Using chart $\mathrm{K}$ of figure 18 to represent the end of the second oscillatory wave, it is seen that the predators survived only in the lower right area of the universe where only a minor portion of the prey was present. With the near annihilation of this localized center of population by the predators, the latter then starved as is shown in the subsequent chart L, although one female predator had wandered off into an area where there was no food but from which position it later moved to the left and located the edge of the main mass of prey (chart M). During this time (charts $\mathrm{K}$ to $\mathrm{M}$ ), the prey increased greatly in the absence of predators in the large area it inhabited. Considering the universes having predators, conditioning of the oranges for the first time became a dominant depressive feature for the prey population.

Shortage of food was the principal reason why the population leveled off at a high density of approximately 1,800 mites per orange-area between December 12 and January 2. Except for the fact that the main masses of the population encountered a shortage of food at that time because of the predators' loss of contact with it (charts L, M, and $\mathrm{N}$ of fig. 18), the numbers almost certainly would have increased to a position approximating at least 2,500 per orange-area. It is probable that such an increase would have contributed to a compensating, slightly earlier rise in the predator population and, consequently, a slightly earlier decline in the prey population. The resultant crash recorded just subsequent to January 2 was largely an effect of predation, although, as stated, the level from which it was initiated would have been higher (and the resultant aftereffect correspondingly more drastic) except for the ameliorating effect of the shortage of food for the prey just prior to that time. During this time and just subsequently, the approximate proportion of conditioned oranges among those which had reached the age for replacement was 38 per cent (see also "Discussion").

Also, during the peak period of the second oscillation there was a substantial but not principal contribution toward leveling off of the prey population at the approximate position of 1,700 mites per orange-area. In this instance, the proportion of conditioned oranges among those removed from the universe was 25 per cent, but the period of this influence was of shorter duration, and the predators earlier achieved more significant contact with the main masses of the prey, thus preventing a greater degree of food conditioning by the prey. In this instance, it is doubtful whether the prey would have increased to a significantly higher level even if the food had not become limiting to this degree. Thus, 75 per cent of the oranges remained unused to a damaging degree for the 56 days they were present in the universe, and predator action was the principal reason for this.

During the initial oscillatory wave, shortage of food did not enter as a contributive factor. Only six of the 120 oranges removed from the universe 
were conditioned, i.e., 5 per cent, 95 per cent remaining unconditioned for the 56 days (in this experiment only) each was present in the universe.

The data of this universe with relation to certain points will be covered further under the section on "Discussion."

\section{DISCUSSION}

\section{The Experimental Data}

Discussed in this section are certain topics pertaining to the data of the various universes (figs. 1 to 18), collectively, and, as well, the significance of these results as exemplifying the role of dispersion in the predator-prey relation.

Since the universe illustrated in figure 18 approaches in result one of the main objectives of this study, those data will be compared with the results in various of the other universes. The arbitrary imposition of wide distribution of both interacting species throughout all sections of the universe in the initial stocking of this universe had several effects which bear a relation to the subsequent events in this universe and to those occurring in other universes otherwise similar: 1) Both species found favorable quantities of food readily at hand for population growth, for during the initial period neither the predator nor the prey faced impediments. 2) The increase in density of the predator in response to increase in density of its prey was immediate. 3) There was very little conditioning of the oranges by the prey during this early phase, for the predators increased their action swiftly and precluded this. 4) The changes in general density of both species during this phase represent rather smooth curvilinear regressions, for the changes in density were relatively simultaneous throughout the universe, with few localized departures from the general pattern (the data thus support the contention that the actual error of sampling is small-see subsection on "Sampling Procedures"). Some of these interrelated points require clarification.

Since in this first oscillation it was not necessary that the predators overcome substantial impediments (with consequent lag effects and losses in numbers) in locating sources of prey, this oscillation is perhaps typical of one where dispersion of food and habitat and the hazards associated with finding them are minimal. In general, the simple universes previously used where the food was massed in one area gave similar results.

On the other hand, the lag effect of predator action exhibited in most of the complex universes discussed earlier, where the colonizing stock of predators was introduced at only a single or very restricted number of positions, is typical of the second and third oscillatory waves in density as shown for this universe (see fig. 18). Furthermore, the gradual, progressive change in the nature of the distributions (from one oscillation to another) in this universe was such that introductions of the predators into more than a limited number of arenas or introductions of the prey into all sections or arenas of universes would appear to create a condition of distribution not at all natural to such interactions of predators and prey. In this still-too-restricted universe, the predators survived the two critical, post-crash periods only at a single arena and in extremely small numbers, perhaps only a single female in each instance, certainly so in the second. During the third critical, post-crash 
phase, all the predators perished. Thus, the time required for the interacting populations to adjust to patterns of spatial and quantitative distribution more characteristic of a predator-prey relation which has come closer to internal balance may be the principal reason why the lag effect was accumulative from oscillation to oscillation.

Regarding the results of the universes illustrated in figures 14 and 15, the significant fact is that the exact course which may be taken locally at such very low levels of density is a product of chance events, the course of which could be best expressed as a probability of occurrence under various stipulated conditions. In the one instance, the prey were annihilated by the predtors, whereas in the other identical universe the predators starved before all the prey were dead, and the prey population then gradually recovered.

Thus, generally, as to whether the participants survive the critical phase and thus make possible the second oscillation is locally a matter of chance, but as the universe considered is increased in complexity and total potentials, the probability that the participants will survive is increased.

In this connection it is obvious that the prey must survive the exploitation by the predator as a prerequisite to any possibility of the predator's survival. Thus, the first object is to devise an ecosystem in which there is a near certainty that the prey will survive. In the first universes employed, this condition was not even approached, but the larger, more complex universe employed (see fig. 18) comes closer to this requirement (but, considering the position of the predator, is still far from adequate).

Obviously, for given conditions, the probability that three or four successive oscillations will occur is progressively more remote and is the product of the separate probabilities of survival of both participants through each component critical phase. This would be true even disregarding the view of Nicholson $(1933,1954)$ that the amplitude of such oscillations will increase with time. If his view is correct and its tenets not modified by damping features, the probability of such a relation continuing for a successively longer number of oscillations would be correspondingly even more reduced. Yet, this cannot be interpreted as contrary to the principle that as density of the prey decreases, the pressure of predator action on it will also decrease.

In this connection, Huffaker and Kennett (1956), as previously stated, demonstrated that biotic interaction between a phytophagous form and its plant host, (with examples which feed in a way as to cause reaction by the plant in a manner as to alter the food potential produced subsequently) may be such that the oscillations in the absence of predation may be of decreasing amplitude, due to progressive weakening of the plants. Franz (in press) also showed that such interaction may predetermine in a rather subtle way the potentials of subsequent populations of plant feeding forms and, correspondingly, the natural enemies which attack them. Such mechanisms tend to reduce the amplitude of predator-prey oscillations as interactions occur between predator actions and nutritional limitations in time and place.

Shortage of food was also discussed in Subsection I of Section II in relation to damping of the amplitude in a predator-prey universe. It should be noted also that in the universe illustrated in figure 12, there was substantial shortage of food for the prey in local arenas, such was the interaction of problems 
of dispersal (in this universe where the oranges were widely dispersed) and predator action (see also Subsection D of Section II). While $1 / 4$ of the orange supply was fully utilized at its replacement, the predators prevented the utilization of the other $3 / 4$ of the food.

Thus, it is obvious that even though action of a predator may be locally insignificant at a given time and compensatory in nature (only a substitute for food conditioning which would surely limit the density there anyway), the predation may be far more significant throughout the larger sphere which would be reached by migrants from the nutritionally overpopulated area. That is, such migrants could proceed to overpopulate the new areas as well but for the predators which preclude the possibility in an example such as this.

This type of control by predation, associated or not with shortage of food for the prey in local arenas, is generally illustrated by the data of this study. The degree of lag in appearance or introduction of the predators into the ecosystem or local arenas is the critical feature of how much of the plant food may be depleted prior to effective curtailment of the plant feeding form. Significantly, in the presence of an effective predator, overpopulation by the plant feeding form in one arena is to a marked degree an assurance against such overpopulation in other arenas. Thus, the common contention by biological control specialists that the farmer should be willing to accept some crop injury is theoretically sound and has been practically demonstrated many times.

In the universes of Subsections A, B, and C of Section II (illustrations of figures 9,10 , and 11 ), the food of the prey was readily accessible, joined and grouped (a minimum of dispersion). In those universes the predators readily found their prey, responded more quickly to changes in density of the prey and were able quickly to destroy them. This condition appears to offer greater likelihood that both the predators and the prey will be annihilated, although in one of the three examples the prey escaped that end.

The occurrence of an almost imperceptible second wave or increase in the universe in which six whole oranges were used (see fig. 11) does not justify the conclusion that simple increase in the area or quantity of food used necessarily greatly increases the chances of creating a self-perpetuating predator-prey system. It is logical to assume that increased complexity is a more important element of the prerequisites than increased area or quantity of food for the prey. Such complexity creates greater relative refuge or protection against the prey's being overexploited, and also reduces its effective reproduction, but it is significant that refuges restrictive to the predators such as envisaged by Gause (1934) and Gause, et al. (1936) are not implied as essential.

Comparatively, increase of a prey population recovering from the effects of extreme predation is much less rapid than that which results when an original colony is started with an equally low number of colonizing individuals. This has been a characteristic feature in these experiments. Examples of this may be seen in figures $9,12,15,16$, and 18 by comparing the steepness of the curves, at the initiation of the universes, with the obviously very gradual increases which resulted from the small numbers which escaped 
the predators at the end of the crashes in the populations and subsequent to starvation of all the predators.

The reason seems to lie with certain undercrowding phenomena and with the fact that very few females escape the predators, and these are often unmated. Unless copulation occurs later they produce only male offspring. If the female survives long enough and remains in the area, promoting likelihood of contact, she may then copulate with one of her own sons or perhaps another male, and female progeny would result. Two or more generations may be required for the population to attain a favorable proportion of fertilized females and, thus, vigorous population growth, even when predators are no longer present.

Another partial explanation is the observed fact that the females which survive are more commonly found on partially or heavily conditioned oranges. On these oranges the presence of a much greater quantity of webbing, cast skins, and bodies of dead mites affords a relative sheltering effect and thus reduces the probability of the predators' destroying the last survivors. These heavily conditioned oranges are very poor sources of food for population increase; hence, a slow recovery results from the survivors.

\section{CONCLUSIONS}

The aforestated considerations suggest that the most satisfactory universe employed (see fig. 18) is still far too restricted, and that, for a perpetuating system, sufficient potentialities must be incorporated to assure several or many such arenas of "last survivors" of predators. This system would leave little probability that all such "last survivors" will simultaneously starve and none find new arenas inhabited by the prey. Thus, there is envisaged in such a system many intergrading, larger, nearly self-sustaining subuniverses or ecosystems, each one as adequate or more adequate than the one illustrated in figure 18.

A major difficulty in demonstrating the existence of reciprocal predatorprey oscillations in nature is associated with the patchy or wavelike occurrence of the predation in time and place, particularly true with examples which are wingless such as the mites and which may have limited extensive dispersal power over distances or from tree to tree, for example. In such studies an inherent oscillatory relation would be confused if the sample area taken to reveal the dynamics of a population unit is too large and, obviously, if it is too small.

Nearly any field entomologist who has studied the action of natural enemies of insect pests has noted that the pattern of action is often patchy in occurrence, proceeding in irregular waves from one or more centers. It is obvious that in one local arena the predator-prey relation may be in one phase of an oscillation while in an adjacent arena it may be in a diametrically opposed phase. Therefore, any combining of two such populations into one would not give a reliable picture of the inherent oscillatory nature of the relation.

Thus, in selecting an environmental area it must be large enough to permit the continued existence of both the predator and its prey, yet not so large 
that the populations in its several sections may proceed asynchronously, due to too limited interchange of the biotic participants.

It is thus more philosophical than factual to discuss whether or not the predator-prey relation is "inherently" disoperative or self-exterminative in arbitrarily restricted environments. To use an extreme example, the end result would be certain if a small universe or enclosure were employed in which only one pair of mountain lions was confined with only one pair of mule deer. Although in the case of this predatory mite and its prey, an orange is a far more nearly adequate base for a suitable ecosystem, yet, on a single orange the predator has invariably overexploited its prey and become exterminated as a local population. With many examples, the prey has been exterminated also, but with others the prey has been able to recover after the starvation of all the predators. Obviously, if the area is sufficiently small and arbitrarily simple, the biological parameters which have been present during the long evolutionary origins of the relations involving the participants are absent, and capture is so simple that the coaction is disoperative. It is necessary that a system be adequate to assure a high probability that some prey will be missed and that somewhere reasonably accessible, but not too readily so, there are local populations of prey which are thriving and sending emigrants to repopulate the depopulated areas. Also, this predator cannot survive on very low populations (although it requires many fewer prey than does the beetle, Stethorus spp., which feeds on the same preysee also Kuenen, 1945), but must contact a fair density of prey at least at small micro-arenas in order to reproduce and survive.

That self-sustaining predator-prey coactions cannot be maintained without "migration" is self-evident. In this type of study the distinction between migration and any movement at all becomes rather ephemeral. The author disagrees that these migrations must be from beyond the limits of a reasonably adequate system. They may be a result of normal movements within the system - if the system is adequate to give expression to the inherent balance in the biological relations of the predator, its prey, and their coinhabited environment. In an unpublished study, the author and C. E. Kennett have demonstrated that a single strawberry plant is an adequate universe during its life span to sustain a predator-prey coaction. No smaller universe utilizing strawberries is conceivable since a single leaf or flower is not a self-perpetuating living unit.

The speed of local-arena extermination by a predator does not define the period of an oscillation. In fact, it appears to bear little relation to that period. Local extermination of the prey on an orange exposing only $1 / 20$ orange area has often occurred within three days of the entry of a female predator in that area. Even if the density of the prey population is high, with several hundreds on such an area, they are often exterminated within a period of five or six days. If the environment considered is increased to a single half-orange unit, the time required for self-extermination has been, on the average, longer. In most of the more complicated environments, and involving at least a 2-orange area, the time required to produce the drastic decline in population sufficiently general to jeopardize the predator's ex- 
istence or cause its extermination has been greatly extended-20 to 40 days for a complicated arrangement involving a single-tray universe and a 2 orange feeding area widely dispersed. The same interval was increased to 30 to 60 days for the most complicated system employing a 6-orange feeding area dispersed over 120 oranges and including a maze-effect of vaseline partial-barriers.

It seems, therefore, that the complexity of the dispersal and searching relationships, combined with the period of time required for the prey species to recover in local arenas from the effects of severe predation and accomplish general repopulation, is more important in determining the period of oscillation than is the intensity of predation once contact is made with local arenas of prey. The rapid recovery of the prey is essential to maintain the predator unless there are arenas of high population which are missed.

It is thought that the existence of barriers increases the chances that the prey species will survive at a level conducive to its rapid recovery. However, it is recognized that the barriers may act as a double-edge sword and defeat the purpose of their use. They do increase the incompleteness of contact and cause marked delay in predator increase. This delay also subsequently causes a greater predator population, which then tends to offset the purpose of the barriers during the crash period. Only further experimentation would really prove whether the barrier feature of this experiment has been a deterrent or an aid to continuance of the coaction. Theoretically, the greater violence of oscillation caused by the barriers would be disoperative in nature, but, on the other hand, they do create the partial asynchrony in geographic position and promote earlier population recovery of the prey species. These features are essential to survival of the predator. They may be more than enough to offset the disoperative pressure created by the higher populations achieved at the crests of population densities. Perhaps, also, the partial ameliorating effect from conditioning of the food in local arenas tends to cancel the greater amplitude otherwise occasioned by the use of the barriers.

The complexity of the environment being searched by both predators and prey lends to the relations a marked inconstancy of hazards from micro-area to micro-area. The idea of a constant area of discovery for the predator or of a constancy in dispersal effectiveness for the prey is difficult to visualize in this environment or in nature. There is not only inconstancy, but nothing resembling a progressive gradation in the hazards. The area of discovery, or that area effectively covered and in which all prey are destroyed by a predator of this species, would vary with its hunger, the density of the prey population independently of hunger of the predator (due to the greater webbing, the added cast skins, debris, et cetera present), the complexity of the general environment with respect to the variability of physical barriers or restrictions of all kinds, and the degree of synchrony in responses, preferences, and tolerances between predator and the prey to such conditions as gravity, light, temperature, moisture, the physical surfaces, air movements, et cetera. The idea of a constant area of discovery has theoretical meaning, particularly where simple, uniform areas are involved to which both predators and prey are rigidly restricted and no chance afforded them to express the broad or narrow ranges of asynchrony in behavior and ecology. 
The author feels that the balance or stability observed in nature is characteristic of the total environments in which the evolution of a relation occurred, and forms related to one another in a manner notable for the lack of stability in the community would tend to be replaced by others whose relations are more stable and, thus, the assets of the environment more efficiently utilized. The same effect would be achieved if they were forced by better adjusted competitors to occupy progressively less significant niches within which adequate stability does prevail. It cannot be overstressed that what happens with one predator-prey relation, in one ecosystem, or under a given environmental complex, as to seasons or period of years, for instance, does not necessarily apply to others.

While these data indicate that, other things being equal, simplified monocultures of crops are likely to have greater problems with insect pests than are diversified plantings, it is, nevertheless, known that a single species of introduced natural enemy has in many cases throughout the world permanently solved the most severe problems relating to such pests of monocultures. In this connection, it is interesting to note that Taylor (1955) expressed the opinion that because of the variety and mosaic of small plantings in Britain, the complex of forces for solid natural control are more favorable than in regions where extensive acreages of monocultures are the rule-the reasons for which he considered are yet unknown.

\section{SUMMARY}

An experimental study of the role of dispersion in the predator-prey relation was made, using the predatory mite, Typhlodromus occidentalis, and the phytophagous mite, Eotetranychus sexmaculatus, as the prey. Earlier experimental work by G. F. Gause and associates had led to some acceptance among ecologists of the view that the predator-prey relation is inherently selfannihilative and that continuation of this relation or coaction is dependent upon either: 1) immigrations into the depopulated areas from without, or 2 ) the existence of definite refuges restrictive to the predators.

In this study, a wide variety of different arrangements in dispersion of plant food (and microhabitat) was tested experimentally. In all the simple universes employed the conclusions of Gause with respect to the predator, but not to the prey, seemed to apply. The unacceptability of that view was demonstrated by the use of a larger, much more complex universe utilizing wide dispersion and incorporating also partial barriers, thus increasing still further the relative dispersion while still not incorporating restrictive refuges. By this method, predator-prey coaction was maintained for three successive oscillations. It is thus quite probable that a controlled, experimental ecosystem can be established in which the predator-prey coaction would not be inherently self-annihilative. It is believed also that various damping mechanisms would come into play which would serve to ameliorate the theoretically sound concept that oscillations arising from this coaction are inherently of increasing severity in amplitude.

The whole controversy becomes rather more philosophical than factual, considering that the earlier view incorporated the purely relative concept of 
immigration of new stock from without, and any distinction between immigration or emigration and any movement at all on the part of the participants can hardly be upheld. The suggestion seems more appropriate that artificial universes are inadequate if they do not give possibility of expression of the major parameters intrinsic to the specific predator-prey coaction in the natural habitat, and that conclusions drawn from such data as to principles have limited value. The success we have in sustaining such a coaction under experimental conditions is probably a measure of the degree to which we have duplicated the inherent essentials.

In this study, arbitrary selection of different degrees of dispersion and segmentation of the units of food for the prey was accomplished without altering the total surfaces to be searched, and, when desired, without altering the total amounts of food used. This was done by covering oranges to various degrees, leaving known exposed portions, and dispersing them as desired among waxed rubber balls of the same size. The technique offers possibilities of elaborate and varied studies along these lines. For example, further modifications could make it possible to study the predator-prey relation with greater assurance against overexploitation, and, thus, various other features, such as the introduction of a competing predatory species or a competing prey species, could be introduced in order to study their relations to the periods and amplitudes of the oscillations. By elaboration along these lines it should be possible to establish empirically whether employment of quite diversified agricultures may offer prospects of relief from insect pestsin comparison with extensive cultivations of single crops. 


\section{REFERENCES}

DeBach, P., and H. S. SMith

1941. Are population oscillations inherent in the host-parasite relations Ecology 22: $363-69$.

ERRINGTON, P.

1937. What is the meaning of predation? Smithsn. Inst. Ann. Rpt. 1936:243-52.

1946. Predation and vertebrate populations. Quart. Rev. Biol. 21:144-77.

FinNey, G. L.

1953. A technique for mass-culture of the six-spotted mite. Jour. Econ. Ent. 46:712-13.

Franz, J.

In Press. The effectiveness of predators and food as factors limiting gradations of Adelges (Dreyfusia) piceae (Ratz.) in Europe. Tenth Inter. Cong. Ent., 1956.

GAuse, G. F.

1934. The struggle for existence. (163 pp.) Williams \& Wilkins, Baltimore. Md.

Gause, G. F., N. P. Smaragdova, and A. A. WitT

1936. Further studies of interaction between predators and prey. Jour. Anim. Ecol. $5: 1-18$.

Huffaker, C. B., and C. E. KennetT

1956. Experimental studies on predation: Predation and eyclamen-mite populations on strawberries in California. Hilgardia 26(4):191-222.

KuENEN, D. J.

1945. On the ecological significance of Metatetranychus ulmi C. L. Koch (Acari, Tetranychidae). Tijdschr. v. Ent. $88: 303-12$.

LEOPOLD, A. S.

1954. The predator in wildlife management. Sierra Club Bul. 39:34-38.

NichOLSON, A. J.

1933. The balance of animal populations. Jour. Anim. Ecol. 2, Supp.:132-78.

1954. An outline of the dynamies of animal populations. Austral. Jour. Zool. 2:9-65.

TAYLOR, T. H. C.

1955. Biological control of insect pests. Ann. Appl. Biol. 42:190-96.

Uvarov, B. P.

1931. Insects and climate. Ent. Soc. London, Trans. 78:1-247.

WATERS, N. D.

1955. Biological and ecological studies of Typhlodromus mites as predators of the sixspotted mite. (Unpublished Ph.D. dissertation, University of California, Berkeley.)

Winsor, C. P.

1934. Mathematical analysis of growth of mixed populations. Cold Spring Harbor Symposia on Quant. Biol. 2:181-89. 

The journal Hilgardia is published at irregular intervals, in volumes of about 600 pages. The number of issues per volume varies.

Subscriptions are not sold. The periodical is sent as published only to libraries, or to institutions in foreign countries having publications to offer in exchange.

You may obtain a single copy of any issue free, as long as the supply lasts; please request by volume and issue number from:
Agricultural Publications
Room 22, Giannini Hall
University of California
Berkeley 4, California

The limit to nonresidents of California is 10 separate issues on a single order. A list of the issues still available will be sent on request. 


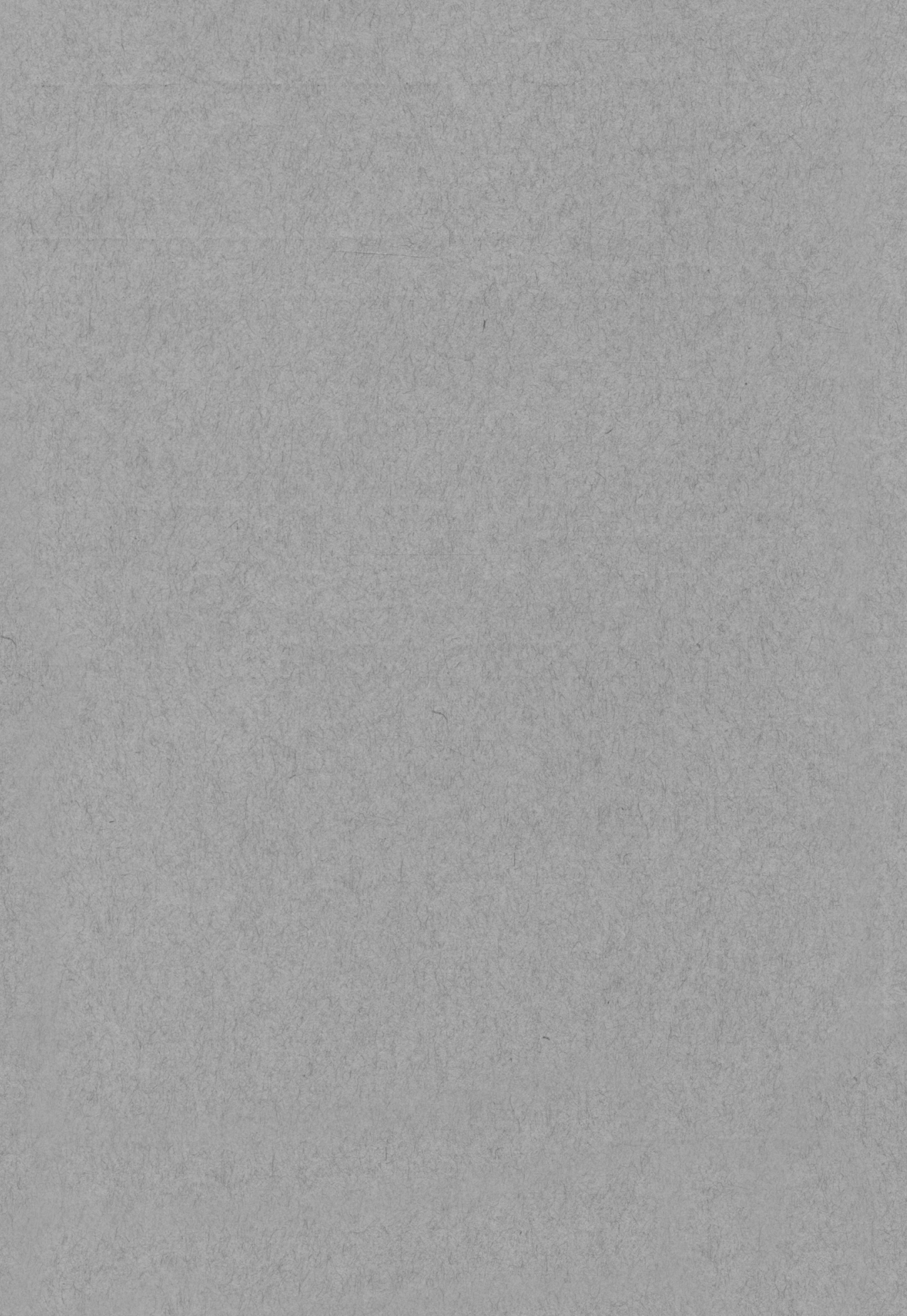

